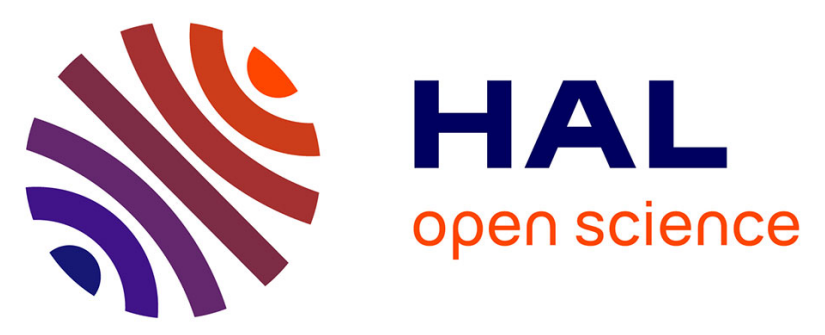

\title{
Diversity of functional alterations of the ClC-5 exchanger in the region of the proton glutamate in patients with Dent disease 1
}

Imène Sakhi, Yohan Bignon, Nadia Frachon, Marguerite Hureaux, Bárbara Arévalo, Wendy González, Rosa Vargas-Poussou, Stéphane Lourdel

\section{To cite this version:}

Imène Sakhi, Yohan Bignon, Nadia Frachon, Marguerite Hureaux, Bárbara Arévalo, et al.. Diversity of functional alterations of the ClC-5 exchanger in the region of the proton glutamate in patients with Dent disease 1. Human Mutation, 2021, 10.1002/humu.24184 . hal-03148953

\section{HAL Id: hal-03148953 https://hal.sorbonne-universite.fr/hal-03148953}

Submitted on 22 Feb 2021

HAL is a multi-disciplinary open access archive for the deposit and dissemination of scientific research documents, whether they are published or not. The documents may come from teaching and research institutions in France or abroad, or from public or private research centers.
L'archive ouverte pluridisciplinaire HAL, est destinée au dépôt et à la diffusion de documents scientifiques de niveau recherche, publiés ou non, émanant des établissements d'enseignement et de recherche français ou étrangers, des laboratoires publics ou privés. 
Diversity of functional alterations of the CIC-5 exchanger in the region of the proton glutamate in patients with Dent disease 1.

Imène Sakhi ${ }^{1,2}$, Yohan Bignon ${ }^{3}$, Nadia Frachon ${ }^{1,2}$, Marguerite Hureaux ${ }^{4}$, Bárbara Arévalo ${ }^{5}$, Wendy González ${ }^{5,6}$, Rosa-Vargas-Poussou ${ }^{1,2,4}$ and Stéphane Lourdel ${ }^{1,2}$

${ }^{1}$ Centre de Recherche des Cordeliers, INSERM, Sorbonne Université, Université de Paris, "Laboratoire Physiologie Rénale et Tubulopathies", F-75006 Paris, France; ${ }^{2}$ CNRS ERL8228, F-75006 Paris, France; ${ }^{3}$ Centre Universitaire des Saints Pères, Université Paris Descartes, INSERM, Paris, France ; ${ }^{4}$ Assistance Publique-Hôpitaux de Paris, Hôpital Européen Georges Pompidou, Département de génétique, Paris, France; ${ }^{5}$ Center for Bioinformatics and Molecular Simulations (CBSM), Universidad de Talca, Talca, Chile ; ${ }^{6}$ Millennium Nucleus of Ion Channels-Associated Diseases (MiNICAD), Universidad de Talca, Talca, Chile

\section{Corresponding author:}

Dr. Stéphane Lourdel

Centre de Recherche des Cordeliers UMR_S 1138, ERL 8228

15, rue de l'école de médecine, 75006 Paris, France

Phone: +33144275117

Email: stephane.lourdel@ sorbonne-universite.fr 


\section{FUNDING INFORMATION}

Imène Sakhi holds a fellowship from the French Ministère de 1'Enseignement Supérieur et de la Recherche. Wendy González research is supported by Fondecyt 1191133 and Fondequip EQM160063. 


\begin{abstract}
Mutations in the CLCN5 gene encoding the $2 \mathrm{Cl}^{-} / 1 \mathrm{H}^{+}$exchanger $\mathrm{ClC}-5$ are associated with Dent disease 1, an inherited renal disorder characterized by low molecular weight (LMW) proteinuria and hypercalciuria. In the kidney, $\mathrm{ClC}-5$ is mostly localized in proximal tubule cells where it is thought to play a key role in the endocytosis of LMW proteins. Here, we investigated the consequences of eight previously reported pathogenic missense mutations of $\mathrm{ClC}-5$ surrounding the "proton glutamate" that serves as a crucial $\mathrm{H}^{+}$-binding site for the exchanger. A complete loss of function was observed for a group of mutants that were either retained in the endoplasmic reticulum of HEK293T cells or unstainable at plasma membrane due to proteasomal degradation. In contrast, the currents measured for a second group of mutations in X. laevis oocytes were reduced. Molecular Dynamics simulations performed on a ClC-5 homology model demonstrated that such mutations may alter $\mathrm{ClC}-5$ protonation by interfering with the water pathway. Analysis of clinical data from patients harboring these mutations demonstrated no phenotype/genotype correlation. This study reveals that mutations clustered in a crucial region of ClC-5 have diverse molecular consequences in patients with Dent disease 1 , ranging from altered expression to defects in transport.
\end{abstract}

Keywords: Dent disease; CLCN5; ClC-5; kidney; proteasome; proton glutamate 


\section{INTRODUCTION}

Dent disease is an X-linked hereditary tubular disorder characterized by low molecular weight proteinuria, hypercalciuria with nephrocalcinosis or nephrolithiasis and progressive renal failure. The disease is genetically heterogeneous: inactivating mutations of the CLCN5 gene (MIM\# 300008) encoding the $2 \mathrm{Cl}^{-} / \mathrm{H}^{+}$exchanger ClC-5 (Dent disease 1, MIM\# 300009) are present in about $60 \%$ of patients harboring mutations (Mansour-Hendili et al., 2015), whereas inactivating mutations of the OCRL1 gene (MIM\# 300535) encoding the phosphatidylinositol-4,5-bisphosphate-5-phosphatase (Dent disease 2, MIM\# 300555) have been detected in about $15 \%$ of patients (Hoopes et al., 2005; Hichri et al., 2011). Up to now, no mutations of these genes have been identified in about $25 \%$ of patients (Mansour-Hendili et al., 2015).

In the kidney, ClC-5 is predominantly found co-localizing with the V-type $\mathrm{H}^{+}$-ATPase and internalized low molecular weight proteins in early endosomes of proximal tubule cells. In addition, ClC-5 is also detected to a lesser extent in the thick ascending limb of Henle's loop and in the intercalated cells of the collecting duct (Gunther et al., 1998; Devuyst et al., 1999; Sakamoto et al., 1999; Piwon et al., 2000). Early results obtained using ClC-5 knockout mice, conditionally immortalized proximal-tubular epithelial cell lines (ciPTECs) from patients with ClC-5 mutations and other cell lines suggested that $\mathrm{ClC}-5$ could play an important role in proximal tubule endocytosis by neutralizing the build-up of positive charges in early endosomes by the V-type $\mathrm{H}^{+}$-ATPase (Gunther et al., 2003; Wang et al., 2005; Gorvin et al., 2013). However, experiments from mice carrying an artificial mutation of the "gating glutamate" p.Glu211Ala (E211A) converting ClC-5 into a pure anion conductance proposed that endocytosis also requires proper endosomal $\mathrm{Cl}^{-}$concentration underlain by $\mathrm{Cl}^{-} / \mathrm{H}^{+}$ exchanger activity of ClC-5 (Novarino et al., 2010). In addition, a defective interaction of ClC5 with other proteins that regulate endocytosis may also be another pathogenic factor (Hryciw 
et al., 2003, 2006, 2012; Reed et al., 2010; Lee et al., 2015). As a whole, these data indicate that the cellular mechanisms by which $\mathrm{ClC}-5$ lead to Dent disease remain incompletely understood.

A series of investigations in heterologous expression systems have described the functional consequences of ClC-5 pathogenic mutations (Grand et al., 2009, 2011; Smith et al., 2009; Tang et al., 2016; Chang et al., 2020). They revealed that most of CLCN5 mutations impair protein processing along the secretory pathway, leading to endoplasmic reticulum (ER) retention and further degradation of the misfolded proteins through the ER-Associated Degradation (ERAD) pathway (class 1). A second group of mutations have also been described for which protein processing and stability of the mature form of $\mathrm{ClC}-5$ is reduced (class 2). Another group of mutations has been associated with altered electrical activity and normal subcellular trafficking (class 3). Among class 3, some mutations resulted in reduced endosomal acidification, whereas another subset of mutants appeared to have no effect on endosomal $\mathrm{pH}$ (Smith et al., 2009; Gorvin et al., 2013; Satoh et al., 2016; Bignon et al., 2018). This latter observation further confirms that defective endocytosis in Dent disease is not necessarily linked to defective endosomal acidification.

Despite numerous reports on the molecular mechanisms underlying Dent disease, there has been so far no investigation focusing on the impact of CLCN5 mutations clustering in a restrained region of ClC-5. In this study, we have analyzed the functional consequences of some pathogenic missense mutations localized in close vicinity of the "proton glutamate" (E268), using X. laevis oocytes and HEK293T cells as heterologous expression systems. The "proton glutamate" is strictly conserved among $\mathrm{ClC} 2 \mathrm{Cl}^{-} / \mathrm{H}^{+}$transporters, and serves as a crucial $\mathrm{H}^{+}$-binding site at their intracellular side (Jentsch and Pusch, 2018). For this purpose, we analyzed eight previously reported $C L C N 5$ missense mutations in this region $[\mathrm{c} .782 \mathrm{G}>\mathrm{A}$, p.Gly261Glu (G261E), c.781G>A, p.Gly261Arg (G261R), c.796C>G, p.Leu266Val (L266V), 
c.799G >A, p.Glu267Lys (E267K), c.801A>C, p.Glu267Asp $\quad$ (E267D), c.808A>G, p.Ser270Gly (S270G), c.814T>A, p.Tyr272Asn (Y272N) and c.817T>C, p.Phe273Leu (F273L)] (Hoopes et al., 2004; Ramos-Trujillo et al., 2007; Tosetto et al., 2009; Bogdanović et al., 2010; Sekine et al., 2014; Mansour-Hendili et al., 2015; Ashton et al., 2018). 


\section{MATERIAL AND METHODS}

\section{Patients}

We retrospectively analyzed individual clinical data of patients of our cohort (D162, D208 and D237), as well as available data of 6 additional patients described in the literature harboring mutants analyzed in this paper. We also performed a genotype-phenotype correlation using the three classes of missense mutations expressed in vitro and available clinical data of the literature of patients harboring these variants. Available data were mainly qualitative and were analyzed for 45 patients with class 1 mutations, 11 with class 2 and 35 with class 3 mutations. The list of mutants by class and publications selected for this analysis are shown in Supp. Table S1.

\section{Molecular biology}

The human coding sequence of ClC-5 (GenBank NM_000084.4) was subcloned either into the pTLN vector (this construction was provided by Thomas J. Jentsch, MDC/FMP, Berlin, Germany) for expression in X. laevis oocytes or into the peGFP vector for expression in HEK293T cells. The coding sequence for GFP in the peGFP vector has been substituted for that of human ClC-5. In both vectors, an HA epitope was introduced between amino acids 107 and 108 of $\mathrm{ClC}-5$. ClC-5 mutants were synthesized from wild-type (WT) ClC-5 sequence through site-directed mutagenesis using the NEB Q5 kit (New England Biolabs, Ipswich, MA) and all the constructs were fully sequenced before use.

\section{Expression in $X$. laevis oocytes}

Capped cRNA were synthesized in vitro from WT and mutant ClC-5 pTLN expression vectors using the SP6 mMessage mMachine Kit (Ambion, Austin, TX). Defolliculated X. laevis 
oocytes (EcoCyte Bioscience, Dortmund, Germany) were injected with 20 ng of the ClC-5 cRNAs and were then kept at $18^{\circ} \mathrm{C}$ in modified Barth's solution containing (in mM): $88 \mathrm{NaCl}$, $1 \mathrm{KCl}, 0.41 \mathrm{CaCl}_{2}, 0.32 \mathrm{Ca}\left(\mathrm{NO}_{3}\right)_{2}, 0.82 \mathrm{MgSO}_{4}, 10 \mathrm{HEPES}, \mathrm{pH} 7.4$, supplemented with 10 $\mathrm{U} / \mathrm{ml}$ of penicillin and $10 \mu \mathrm{g} / \mathrm{ml}$ of streptomycin (Thermo Fisher, Waltham, MA).

\section{Electrophysiology}

Two-electrode voltage-clamp experiments were performed at room temperature using a TEV-200A amplifier (Dagan, Minneapolis, MN) and PClamp 10 software (Axon Instruments, Foster City, CA), 48 hours after oocytes injection. Pipettes whose resistance was less than $1 \mathrm{M} \Omega$ were filled with $3 \mathrm{mM} \mathrm{KCl}$. Currents were recorded in ND96 solution containing (in mM): $96 \mathrm{NaCl}, 2 \mathrm{KCl}, 1.5 \mathrm{CaCl}_{2}, 1 \mathrm{MgCl}_{2}, 5 \mathrm{HEPES}, \mathrm{pH}$ 7.4. Currents were recorded in response to a voltage protocol consisting of $20 \mathrm{mV}$ steps from $-100 \mathrm{mV}$ to +100 $\mathrm{mV}$ during $800 \mathrm{~ms}$ from a holding potential of $-30 \mathrm{mV}$.

\section{Cell culture and transfection}

HEK293T cells were grown in DMEM+GlutaMAX culture medium (Gibco, Carlsbad, CA) supplemented with $10 \%$ fetal bovine serum (S51940-1879 Eurobio, Les Ulis, France), penicillin $(100 \mathrm{U} / \mathrm{ml})$ and streptomycin $(100 \mathrm{mg} / \mathrm{ml})$ at $37^{\circ} \mathrm{C}$ in $5 \% \mathrm{CO}_{2}$. Cells were transiently transfected in 6-well plates using 1000 ng of plasmid and X-tremeGENE 9 DNA transfection reagent (Sigma-Aldrich, St. Louis, MO) according to the manufacturer's instructions. At each passage, cells were trypsinized with $0.25 \%$ trypsine and used until passage 15 .

\section{Cycloheximide-chase assay}

Twenty-four hours after transfection, HEK293T cells were incubated with $100 \mu \mathrm{g} / \mathrm{ml}$ cycloheximide during $0,1,3,8$ or 24 hours. Cells were then rinsed three times with PBS at 
room temperature, and cell lysates were prepared and analyzed by western blot as described below.

\section{Investigation on Protein degradation}

Twenty-four hours after transfection, HEK293T cells were treated with $20 \mu \mathrm{M}$ of the proteasome inhibitor MG132 (Sigma-Aldrich) for $3 \mathrm{~h}$ at $37^{\circ} \mathrm{C}$. Lysosomal degradation of WT and mutant ClC-5 was investigated by treating HEK239T cells with $100 \mu \mathrm{M}$ leupeptin (SigmaAldrich) for $3 \mathrm{~h}$ at $37^{\circ} \mathrm{C}$. Cells lysates from the two treatments were subjected to a western blot analysis as described below. The total abundance of the mature and immature forms of WT and mutant ClC-5 were compared in the presence of MG132 or leupeptin and quantified using the ImageJ freeware (NIH, Bethesda, MD).

\section{Surface biotinylation of HEK293T cells}

Forty-eight hours after transfection cells plated onto glass coverslips in 6-well plates were placed 30 minutes on ice and rinsed twice with a cold rinsing PBS solution at $\mathrm{pH} 8.0$ supplemented with $100 \mathrm{mM} \mathrm{CaCl} 2$ and $1 \mathrm{mM} \mathrm{MgCl} 2\left(\mathrm{PBS}^{++}\right)$. In order to label cell surface proteins, cells were incubated at $4^{\circ} \mathrm{C}$ for $1 \mathrm{~h}$ with $\mathrm{PBS}^{++}$containing $1.5 \mathrm{mg} / \mathrm{ml} \mathrm{NHS-LC-biotin}$

(Pierce, Rockford, IL). To remove excess of biotin, cells were then quickly submitted three times to a quenching solution containing $100 \mathrm{mM}$ glycine diluted in $\mathrm{PBS}^{++}$. Then, they were washed three times in ice cold $\mathrm{PBS}^{++}$and fixed in $4 \%$ paraformaldehyde for 15 min prior to immunocytochemistry.

\section{Immunocytochemistry}

Forty-eight hours after transfection, HEK293T cells plated onto glass coverslips in 6well plates were washed with PBS, fixed in $4 \%$ paraformaldehyde and permeabilized with 0.1 
$\%$ TritonX100 for $1 \mathrm{~min}$. Nonspecific antibody binding sites were blocked with $10 \%$ goat serum (Sigma-Aldrich, SLBR1636V). Primary antibodies were mouse anti-HA (SigmaAldrich, St. Louis, MO; 1:200), rabbit anti-EEA1 (Cambridge, UK; 1:200), rabbit anti-calnexin (Stressgen, Ann Arbor, MI; 1:200). FITC-conjugated goat anti-mouse (Jackson ImmunoResearch; 1:250), Alexa Fluor 555-conjugated goat anti-rabbit (Thermo Fisher Scientific, Rockford, US; 1:200), or Cy5-conjugated streptavidin (Sigma-Aldrich; 1:200) were added to the cells as secondary antibodies. Labeled cells were observed and photographed using a LSM710 confocal laser-scanning microscope (Zeiss, Oberkochen, Germany).

\section{Protein isolation}

Forty-eight hours after transfection, total cell lysates were isolated from HEK293T cells plated in 6-well plate by incubation during $10 \mathrm{~min}$ on ice with a lysis solution containing 150 $\mathrm{mM} \mathrm{NaCl}, 50 \mathrm{mM}$ Tris-HCl, $1 \mathrm{mM}$ EDTA, $1 \%$ NP-40, $0.2 \%$ SDS, pH 6.8, and a Complete EDTA free protease inhibitor mix (Roche Diagnostics). After a mechanic lysis through $23 \mathrm{G}$ needles, proteins were solubilized by gentle agitation in lysis solution during $30 \mathrm{~min}$ at $4{ }^{\circ} \mathrm{C}$ and lysates were then centrifuged at $5000 \mathrm{~g}$ during $10 \mathrm{~min}$ at $4{ }^{\circ} \mathrm{C}$. Protein concentration in the resulting supernatant was quantified using the BCA protein assay quantification kit (Pierce).

\section{Western blot analysis}

Ten to thirty micrograms of total proteins were separated on an $8 \%$ SDS-PAGE gel and transferred to nitrocellulose membranes. The blocking solution contained $5 \%$ of nonfat milk proteins added in a TBS $+0.05 \%$ Tween 20 washing buffer. Primary antibodies were monoclonal rat 3F10 anti-HA (Roche Diagnostics; $1: 1000$ ), polyclonal rabbit anti- $\beta$ actin (Abcam, Cambridge, UK; 1:20000). Horseradish Peroxidase-conjugated secondary antibodies were goat anti-rat (Jackson ImmunoResearch; 1:10000), and goat anti-rabbit (Abcam, 
Cambridge, UK). Antibodies were diluted in TBS blocking solution, and incubated overnight at $4^{\circ} \mathrm{C}$ or $1 \mathrm{~h}$ at room temperature. Protein detection was performed using the ECL Western Blotting Substrate (Thermo Fisher). The protein signal was quantified using the ImageJ freeware.

\section{Homology model of hClC-5 channel and molecular dynamics simulations}

To build ClC-5 homology model, the sequence of hClC-5 (NCBI code AAI30432.1) was used. The crystallographic data of the chloride channel from Cyanidioschyzon merolae was employed as template (PBD ID: 3ORG) (Feng et al., 2010). The model was built and optimized using the ICM software (Abagyan and Totrov, 1994). The model was embedded into a pre-equilibrated POPE (1-Palmitoyl-2-oleoyl-sn-glycero-3-phosphoethanolamine) bilayer, then the system was solvated using the TIP3P (transferable intermolecular potential with 3 points) water model. Two $\mathrm{Cl}^{-}$ions were placed at sites $\mathrm{S}_{\mathrm{ex}}$ and $\mathrm{S}_{\text {in }}$ (Feng et al., 2010). The system was neutralized by adding $\mathrm{Cl}^{-}$and $\mathrm{Na}^{+}$ions. To achieve optimal structural and energetically validated model, hClC-5 was subjected to an equilibration by $20 \mathrm{~ns}$ in NPT ensemble with positional restraints of $1.0 \mathrm{kcal} * \mathrm{~mol}-1 * \AA-2$ on the secondary structure of the protein and $\mathrm{Cl}^{-}$ions at sites $\mathrm{S}_{\mathrm{ex}}$ and $\mathrm{S}_{\mathrm{in}}$. Temperature and pressure were kept constant at $300 \mathrm{~K}$ and 1.01325 bar, respectively by coupling to a Nose-Hoover Chain thermostat and MartynaTobias-Klein barostat (Martyna et al., 1994) with an integration time step of 2 fs. Then, positional restraints were removed, and a molecular dynamics simulation of $100 \mathrm{~ns}$ was done per system using a NP $\gamma \mathrm{T}$ (semi-isotropic ensemble) with constant surface tension of 0.0 bar. Molecular dynamics simulations were performed using Desmond software v2019-1 (Bowers et al., 2006) and OPLS2005 force field (Kaminski et al., 2001). To analyze the effect of the mutations, computational mutagenesis was performed on both chains of the dimer (chain A and B) using the residue scanning module of BioLuminate contained in Maestro (Schrödinger 
Release 2017-1, New York, USA). The mutant models were inserted into the membrane and equilibrated following the same protocol as applied for wild-type $\mathrm{ClC}-5$.

It is assumed that in $\mathrm{ClC}$ channels the $\mathrm{Cl}^{-}$ions transport is coupled with the movement of protons (Maduke et al., 2000; Miller, 2006; Chen and Hwang, 2008). The "proton glutamate" takes a proton from the intracellular side and moves it via a water wire to the "gating glutamate" (Chavan et al., 2020). The Class 3 mutants described in this study are nearer the "proton glutamate" than the "gating glutamate" (Supp. Table S2). In consequence, we analyzed the effect of class 3 mutations around the "proton glutamate". During molecular dynamics simulations, water molecules were calculated at $5 \AA$ around the "proton glutamate" (E268) in wild-type, p.Glu268Ala mutant and class 3 mutants using a $t c l$ script in VMD software (Humphrey et al., 1996). To study the effect of class 3 mutations on the "proton glutamate", the pKa value of E268 residue was predicted with PropKa v3.1 (Olsson et al., 2011; Søndergaard et al., 2011) for wild-type and each mutant. To perform this calculation, we collected 100 frames in each system. The whole system (protein, membrane, solvent and ions) was considered for the calculation using an in-house script. The calculations of the amount of water molecules around E268 residue and its pKa value compromise the evaluation of only monomer A as it had been done previously for molecular dynamics calculations (Lee et al., 2016) because $\mathrm{ClC}$ functions as a monomer (Robertson et al., 2010). Salt bridges were determined in monomer A during molecular dynamics simulations using VMD software (Humphrey et al., 1996) and a distance cut-off of $3.3 \AA$.

\section{Statistics}

Results are shown as mean \pm SEM. $n$ indicates the number of experiments. For functional analysis in heterologous expression systems, statistical significance was analyzed 
by paired Student's $t$-test, by Mann-Whitney test, one or two way ANOVA followed by Bonferroni or Dunnett post-tests. A value of $P<0.05$ was considered significant. For molecular dynamics simulations, the Welch's ANOVA non-parametric test was used to determine if there were significant differences in the amount of water molecules around residue 268 and a posthoc analysis was performed using the Games-Howell test. 


\section{RESULTS}

\section{The mutations alter currents of $\mathrm{ClC}-5$ to a variable extent}

In a first series of experiments, we investigated the electrophysiological properties of wild-type (WT) and ClC-5 mutants using two electrode voltage-clamp recordings in X. laevis oocytes. In agreement with previous reports, WT ClC-5 displayed strongly outwardly rectifying currents (Figure 1A and B) (Steinmeyer et al., 1995; Picollo and Pusch, 2005; Scheel et al., 2005; Grand et al., 2009, 2011; Bignon et al., 2018). Compared with WT ClC-5, currents recorded with the p.Leu266Val, p.Tyr272Asn and p.Phe273Leu mutants were significantly reduced by $51.2 \%, 57.8 \%$ and $49.8 \%$, respectively at $+100 \mathrm{mV}$. Those with the p.Ser270Gly mutant were significantly less reduced, as they were only decreased by $18.2 \%$ at $+100 \mathrm{mV}$ (Figure 1C). However, these four mutations preserved the typical voltage dependence of $\mathrm{ClC}$ 5. In contrast, we failed to record any ClC-5 current in oocytes injected with the p.Gly261Arg and p.Glu267Asp mutants: current recordings were undistinguishable from those observed in non-injected oocytes (Figure 1A and C). The p.Gly261Glu mutant was also found to be nonfunctional, as already reported using whole-cell patch-clamp recordings in HEK293T transfected cells (Wojciechowski et al., 2018). To further analyse our data, we performed the estimation of the gating charge of WT and mutants ClC-5 with reduced currents. To do so, we measured the surface under the off-gating currents and divided the resulting value by the current amplitude at $+100 \mathrm{mV}\left(\mathrm{Q}_{\text {off }} / \mathrm{I}_{@+100 \mathrm{mV}}\right)$ for each $\mathrm{ClC}-5$ as previously performed by others (Zifarelli et al., 2012; Alekov, 2015). For the p.Leu266Val, p.Tyr272Asn and p.Phe273Leu

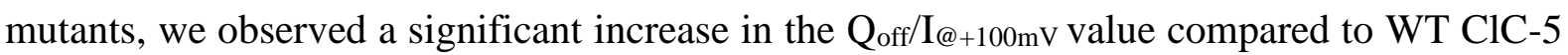
(Figure 1D). Regarding the inverse relationship between the gating charge and the probability of ClC-5 to transport ions, the diminution in the currents amplitude of these mutants can be 
explained by a decreased transport cycle of ClC-5. However, the p.Ser270Gly ClC-5 mutant led to a non significant alteration of this parameter (Figure 1D).

\section{Some mutations result in endosplamic reticulum retention}

To evaluate whether altered currents carried by the ClC-5 mutants were caused by a modification of its subcellular localization, we examined transiently transfected HEK293T cells by immunostaining. As expected from previous reports (Grand et al., 2009; Smith et al., 2009; Alekov, 2015; Tang et al., 2016; Bignon et al., 2018), immunocytochemistry analysis revealed a colocalization between WT ClC-5 and biotinylated cell-surface proteins, the early endosomal marker EEA1 but not with the ER marker calnexin (Figure 2). The p.Leu266Val mutant (Figure 2), as well as the p.Ser270Gly, p.Tyr272Asn and p.Phe273Leu mutants (Supp. Figure S1) displayed a similar distribution. In contrast, as shown by their colocalization with calnexin, the p.Glu267Lys (Figure 2) along with the p.Gly261Arg mutant (Supp. Figure S1) were retained in the ER and were excluded from the plasma membrane and the early endosomes. In accordance with the literature (Wojciechowski et al., 2018), the p.Gly261Glu mutant was also shown to be retained in the ER (Supp. Figure S1). Finally, the p.Glu267Asp mutant co-localized with both EEA1 and calnexin markers. Taken together, these data strongly suggest that the reduced current amplitude for the p.Leu266Val , p.Glu267Asp, p.Ser270Gly, p.Tyr272Asn and p.Phe273Leu mutants could not be attributed to a defect of protein trafficking to the cell surface. In contrast, abolition of currents for the p.Gly261Glu and p.Gly261Arg mutants results from ER retention of $\mathrm{ClC}-5$.

\section{Defective glycosylation of CIC-5 occurs in ER-retained mutants}

To further document the cellular mechanisms involved in ClC-5 dysfunction, we next investigated the impact of the mutations on $\mathrm{ClC}-5$ protein expression. For this purpose, total 
cells lysates from transiently transfected HEK293T cells were subjected to a western blot analysis (Figure 3). In agreement with previous reports (Grand et al., 2009, 2011; Bignon et al., 2018), WT ClC-5 expression results in a positive staining for a $\sim 75 \mathrm{kDa}$ core-glycosylated form and a $\sim 90-110 \mathrm{kDa}$ complex glycosylated form, which were absent in protein extracts from mock cells. We previously demonstrated that the $\sim 75 \mathrm{kDa}$ immature form of $\mathrm{ClC}-5$ remains in the ER, whereas the $\sim 90-110 \mathrm{kDa}$ mature form of ClC-5 protein is expressed at the cell surface and on early endosomes (Figure 3A) (Grand et al., 2009). We observed no significant difference in immunoreactivity (neither qualitatively nor quantitatively) between WT ClC-5 and the p.Leu266Val, p.Ser270Gly, p.Tyr272Asn and p.Phe273Leu mutants. Thus, the decreased currents observed with these mutants were not attributable to different protein expression levels. In contrast, only the immature form of ClC-5 was observed with the p.Gly261Arg and p.Glu267Lys mutants, which produced no currents. The p.Gly261Glu was also improperly glycosylated, as previously reported (Wojciechowski et al., 2018). Quantification of the total protein amount revealed that the protein expression level of these mutants was $\sim 20-30 \%$ of that of WT ClC-5. In addition, overexpression of the non-conductive p.Glu267Asp mutant strikingly decreased the amount of the total $\mathrm{ClC}-5$ protein by $\sim 50 \%$ (Figure 3B). Analysis of the immunoblotting revealed that the p.Glu267Asp mutation induced a decrease of the mature form of ClC-5 by 50\% (Figure 3C), but had no significant effect on the immature form of $\mathrm{ClC}-5$. Thus, the decrease in the expression of the mature form of the p.Glu267Asp mutant could explain reduced but not abolished currents of ClC-5.

\section{The proteasome promotes the degradation of the CIC-5 mutants}

A rapid degradation by the ERAD pathway of cells in response to ER retention could contribute to the abolished or reduced expression of the mature form of the p.Gly261Glu, p.Gly261Arg and p.Glu267Lys mutants as detected by immunoblotting. In this view, similar 
cellular mechanisms were obtained with other ClC-5 mutations (Grand et al., 2009, 2011). To directly examine the effects of the mutations on the degradation and the maturation of $\mathrm{ClC}-5$, we performed a cycloheximide-chase analysis. In these experiments, cycloheximide was added $24 \mathrm{~h}$ after transfection to block protein synthesis, and at various times after addition of the inhibitor, ClC-5 expression levels were monitored by immunoblotting. As illustrated in Figure 4, the immature form of the p.Gly 261 Glu mutant was decreased by $\sim 90 \%$, in comparison to $\sim 70 \%$ decrease observed for its WT counterpart after $24 \mathrm{~h}$ of treatment with cycloheximide ( $n$ =4). Kinetics analysis revealed that the half-life of the immature p.Gly261Glu mutant and WT ClC-5 was $\sim 1 \mathrm{~h}$. In contrast, the half-life of the immature form of p.Glu267Asp mutant was a little higher from that of WT ClC-5 $(n=4)$. However, the expression of the mature form of the p.Glu267Asp mutant was reduced by $95 \%$ at the end of the chase period in comparison to WT ClC-5. The half-life of the mature form of the p.Glu267Asp mutant was $\sim 70 \%$ shorter than that of WT ClC-5 (5 hours vs 15 hours, respectively). Taken together, these results demonstrate that the p.Gly261Glu, p.Gly261Arg and p.Glu267Lys mutations lead to inefficient processing of $\mathrm{ClC}-5$ due to rapid degradation by the cells secondary to ER retention, while the p.Glu267Asp mutation results in a strongly decreased stability of the mature form of ClC-5.

We next investigated degradation pathways of one out of the two mutants displaying only the core-glycosylated form of ClC-5 (p.Gly261Glu) and of the mutant showing a reduction in the total protein amount of ClC-5 (p.Glu267Asp ). In most cases, the cellular mechanism of protein clearance involves the activation of the proteasome proteolysis and/or the lysosome machinery (Guerriero and Brodsky, 2012). To identify the degradation pathway, transfected HEK293T cells were treated with $20 \mu \mathrm{M}$ of the proteasome inhibitor MG132 or $100 \mu \mathrm{M}$ of the lysosome inhibitor leupeptin and their protein lysates were subjected to western blot analysis. As depicted in Figure 5, exposure to MG132 increased the protein levels of the total abundance of WT, p.Gly261Glu and p.Glu267Asp ClC-5 but failed to restore expression of their mature 
forms-(Figure 5B). These results demonstrate that the p.Gly261Glu and p.Glu267Asp mutants are degraded by the proteasome, supporting a previous report of two other ClC-5 mutants displaying ER retention and subsequent defective processing (D'Antonio et al., 2013). In contrast to MG132, leupeptin had no effect on total protein expression of WT and mutants ClC5 (Figure 5), indicating that the lysosomal pathway is not involved in the degradation of these mutants $(n=3)$.

\section{Class 3 mutations close to the "proton glutamate" modify the environment around E268}

Class 3 mutations have been associated with altered electrical activity and normal subcellular trafficking. To understand the molecular mechanisms behind this phenomenon, we built a ClC-5 homology model and performed Molecular Dynamic (MD) simulations of ClC5 WT, our class 3 mutants (p.Leu266Val, p.Ser270Gly, p.Tyr272Asn and p.Phe273Leu) and the p.Glu268Ala mutant leading to a complete loss of electrical activity. The generated RMSD graphs show the stability of the protein during MD measurements (Supp. Figure S2).

Proton transference (PT) in ClC channels occurs in two steps: (1) one that implicates a salt bridge dissociation (Lee et al., 2016) and (2) the PT per se via water wires from the "proton glutamate" to the "gating glutamate" (Chavan et al., 2020). On that way, we studied both steps in ClC-5 WT, in class 3 mutants and when it was necessary, we compared these results with those of the p.Glu268Ala MD simulation. On that sense, we observed a pKa shift of E268 residue in class 3 mutations systems to higher values (Table 1 and Figure 6) which means that the deprotonated population of E268 residues is higher in the WT than in class 3 mutants, where the protonated form of E268 is more abundant.

The first step (salt bridge dissociation) is also affected in class 3 mutants. A salt bridge between E268 residue and K174 residue (Figure 7) is present in WT but not in the class 3 mutants during MD simulations except in p.Phe273Leu (Table 2). 
Regarding the second step, the PT per se via water wires from the "proton glutamate" to the "gating glutamate", we measured the amount of water molecules around the "proton glutamate" (E268 residue) in WT, class 3 mutations and p.Glu268Ala mutant. In the p.Glu268Ala ClC-5, the number of water molecules in a sphere of $5 \AA$ diminishes more than two times in average. In class 3 mutants of ClC-5, the number of water molecules around E268 is also reduced in average (Table 3 ). Hence, we observe globally, in class 3 mutations, a diminution in the water availability to establish a water pathway allowing these main glutamate residues connection.

\section{Mutations close to the "proton glutamate" lead to heterogeneous phenotypes}

The analysis of clinical data at diagnosis in our patients and available individual data of patients described in the literature, harboring pathogenic missense variants located in close vicinity of the "proton glutamate" is summarized in Table 4 (Hoopes et al., 2004; RamosTrujillo et al., 2007; Tosetto et al., 2009; Bogdanović et al., 2010; Ashida et al., 2014; Sekine et al., 2014; Mansour-Hendili et al., 2015; Ashton et al., 2018). The clinical presentation in this group of patients reflects the phenotypic heterogeneity previously described in Dent disease 1. The number of patients is too small to perform an analysis of data according to the mutant class: four patients with class 1 mutants, one patient with class 2 mutant and four patients with class 3 mutants (Supp. Table S3). Nevertheless, when data of all patients harboring the missense mutants with in vitro studies allowing them to be classified in one of these three classes are compared, there are no differences in terms of age, renal impairment and presence of nephrocalcinosis or rickets at diagnosis (Supp. Figure S3 and Supp. Table S3). Likewise, 
data of patients with mutations in the "proton glutamate" region show similar spread to other patients (Supp. Figure S3).

\section{DISCUSSION}

In this study, we evaluated the functional consequences of eight CLCN5 missense mutations that had been previously published (p.Gly261Glu, p.Gly261Arg, p.Glu267Asp, p.Glu267Lys, p.Leu266Val, p.Ser270Gly, p.Tyr272Asn and p.Phe273Leu) (Hoopes et al., 2004; Tosetto et al., 2009; Bogdanović et al., 2010; Sekine et al., 2014; Mansour-Hendili et al., 2015). We show that mutants in this region belong to different classes: p.Gly261Glu, p.Gly261Arg, and p.Glu267Lys are class 1 mutants; p.Glu267Asp is a class 2 mutant and p.Leu266Val, p.Ser270Gly, p.Tyr272Asn and p.Phe273Leu are class 3 mutants.

The p.Gly261Glu, p.Gly261Arg, p.Glu267Asp and p.Glu267Lys mutations are located within $\alpha$-helix $\mathrm{H}$, which is involved in the formation of the dimer interface of $\mathrm{ClC}-5$, as well as $\alpha$-helices B, I, O, P and Q (Dutzler et al., 2002, 2003; Wu et al., 2003; Feng et al., 2010). In the case of mutations affecting protein sequence at position 261, it may be anticipated that replacement of small and hydrophobic glycine by amino acids with a larger side chain negatively (glutamic acid) or positively charged (arginine) would alter the helical structure of the $\alpha$-helix and therefore interfere with the dimerization between the monomers. In this view, previous modeling studies have hypothesized that CLCN5 mutations clustering at the interface may impair monomer dimerization of $\mathrm{ClC}-5$ by altering the helical structure of the $\alpha$-helices (Wu et al., 2003; Smith et al., 2009). This could therefore lead to the formation of improperly folded mutant proteins in the endoplasmic reticulum, which would be then subjected to rapid degradation within the cell. Our immunocytochemical and biochemical analyses in HEK293T transfected cells are in accordance with these studies, inasmuch as we demonstrated that the 
p.Gly261Glu and p.Gly261Arg displayed loss of cell surface and early endosomes trafficking, retention in the endoplasmic reticulum, and rapid degradation by the proteasome.

The p.Glu267Lys mutation also resulted in defective N-glycosylation and thus in endoplasmic reticulum expression HEK293T transfected cells. In contrast, the p.Glu267Asp mutant was shown to retain partial trafficking to the cell surface, and was distributed in the early endosomes. The expression of the mature, complex glycosylated form of this mutant was, however, reduced in comparison to those of WT ClC-5. The cycloheximide-chase analysis demonstrated that this could be explained by a decreased stability of the mature form of ClC5. As for the p.Gly261Glu and p.Gly261Arg mutants, one could predict that the p.Glu267Lys mutation may significantly affect the stability of $\alpha$-helix $H$, and consequently monomer dimerization by substituting a negatively charged amino acid (glutamic acid) to an amino acid with a larger side chain which is positively charged (lysine). In contrast, the change of glutamate for an amino acid with a smaller negatively charged side chain (aspartic acid) may induce a minor disruption in $\alpha$-helix structure, allowing ClC-5 residual function. We also investigated the functional effects of another missense mutation (p.Leu266Val) mapping to $\alpha$ helix H. The biochemical and immunofluorescence experiments showed that protein expression and subcellular localization of the ClC-5 mutant were not affected, and the twoelectrode voltage-clamp recordings demonstrated that the currents of the mutant were reduced. Our findings with the above mutations, together with previous functional data in heterologous expression systems (Lourdel et al., 2012) further confirm that mutations clustering at the dimer interface do not necessarily lead to a major alteration in $\mathrm{ClC}-5$ function.

Three other missense mutations (p.Ser270Gly, p.Tyr272Asn and p.Phe273Leu) that we have investigated involve residues positioned in the loop between $\alpha$-helixes $\mathrm{H}$ and I of ClC-5. These mutants exhibited complex glycosylation, plasma membrane and early endosomes expression. Furthermore, electrophysiological recordings in X. laevis oocytes demonstrated 
that the mutations resulted in decreased ionic currents of $\mathrm{ClC}-5$, indicating that these mutations cause fewer defects on ClC-5 structure. The analysis of the gating charge of the p.Leu266Val, p.Tyr272Asn and p.Phe273Leu mutants demonstrated that these ClC-5 display a reduced ion transport cycle. In comparison to the p.Tyr272Asn and p.Phe273Leu mutants, a significant ionic transport remained for the p.Ser270Gly mutant, as the amplitude of the electrical current was only decreased by less than $20 \%$ compared to WT ClC-5. Besides, p.Ser270Gly showed no alteration in the electrogenic transport cycle of ClC-5 in Xenopus oocytes. Knowing that this residue is exposed to the intracellular compartment of the cell, it could be phosphorylated by Serine-Threonine Kinases that may play a role in the regulation of ion transport through ClC-5. The mutation of this aminoacid might affect the phosphorylation site, thus altering this regulatory pathway. To our knowledge, this previously reported mutation (Hoopes et al., 2004) is the only identified CLCN5 variant causing mild defects in ClC-5 function in heterologous expression systems.

Previous studies showed no correlation between genotype and phenotype in Dent disease 1. A phenotypic variability is also observed inside of each of 3 classes of mutants according with their functional consequences. Mutants located in the "gating glutamate" region belong to classes 1, 2 and 3 reflecting different pathophysiological mechanisms. Phenotypic characteristics of patients harboring mutants in this region are also heterogeneous and noncorrelated with the genotype.

MD simulations performed in this study show that class 3 mutants modify the pKa of E268 residue affecting the two steps of the Proton Transference (PT): the salt bridge K174E268 and the PT per se via water wires from the "proton glutamate" to the "gating glutamate".

Class 3 mutants modify the pKa value of the "proton glutamate" in the sense that favors the neutral state (i.e. increase in $\mathrm{pKa}$ ). When the "proton glutamate" is deprotonated, which is more likely to occur in WT than in class 3 mutations, it forms a salt bridge with the positively 
charge of $\mathrm{K} 174$ in the monomer A. A similar interaction is present in $\mathrm{ClC}$-ec1 between the "proton glutamate" (E203) and R28 in monomer B. When E203 accepts a proton from the intracellular side, R28 disrupts its salt bridge with E203 and the "proton glutamate" moves closer to E113 of monomer A (Lee et al., 2016). Curiously, in ClC-5 the position of R28 is replaced by a serine (S50) and E113 is substituted by K174 (Dutzler et al., 2002). Then, we hypothesized that ClC-5 evolves from E268(0) to E268(H) when it accepts a proton from the intracellular side, K174-E268 salt bridge is broken, and then E268(H) transfers through a water wire the proton to the "gating glutamate". In class 3 mutations, E268 is less probable to accept the proton from the intracellular side to initiate ion permeation because the E268 protonated population in these mutations is higher than in WT.

When the "proton glutamate" (E268 in ClC-5) receives the proton from the intracellular side, it transfers the proton to the "gating glutamate" (E211 in ClC-5) (Lee et al., 2016). As E268 and E211 are separated by $12,77 \pm 0.84 \AA$, water molecules occupy this area to facilitate proton transference (Chavan et al., 2020). In the p.Glu268Ala ClC-5, the number of water molecules in a sphere of $5 \AA$ diminishes more than two times in average. In the class 3 mutants of ClC-5, the number of water molecules around E268 is also reduced in average (Table 3). Hence, we observe globally, in class 3 mutations, a diminution in the water availability to establish a water pathway allowing these main glutamate residues connection.

\section{ACKNOWLEDGMENTS}

We thank Prof. Thomas J. Jentsch for kindly providing the HA-tagged ClC-5, Christophe Klein (Cellular Imaging and Histology facility, Centre de Recherche des Cordeliers, Paris, France) for excellent technical assistance in confocal microscopy. We also thank Rodolfo 
Briones and Julio Caballero and Mauricio Bedoya (CBSM, Universidad de Talca) for their helpful advice in molecular dynamics simulation analyses.

\section{CONFLICT OF INTEREST}

The authors declare that there are no conflict of interest.

\section{DATA AVAILABILITY STATEMENT}

The data that support the findings of this study are available on request from the corresponding author. 


\section{REFERENCES}

Abagyan R, Totrov M. 1994. Biased probability Monte Carlo conformational searches and electrostatic calculations for peptides and proteins. J Mol Biol 235:983-1002.

Alekov AK. 2015. Mutations associated with Dent's disease affect gating and voltage dependence of the human anion/proton exchanger ClC-5. Frontiers in physiology 6:159.

Ashida A, Yamamoto D, Nakakura H, Shirasu A, Matsumura H, Sekine T, Igarashi T, Tamai H. 2014. Molecular effect of a novel missense mutation, L266V, on function of ClC-5 protein in a Japanese patient with Dent's disease. Clin Nephrol 82:58-61.

Ashton EJ, Legrand A, Benoit V, Roncelin I, Venisse A, Zennaro M-C, Jeunemaitre X, Iancu D, Van't Hoff WG, Walsh SB, Godefroid N, Rotthier A, et al. 2018. Simultaneous sequencing of 37 genes identified causative mutations in the majority of children with renal tubulopathies. Kidney Int 93:961-967.

Bignon Y, Alekov A, Frachon N, Lahuna O, Jean-Baptiste Doh-Egueli C, Deschênes G, Vargas-Poussou R, Lourdel S. 2018. A novel CLCN5 pathogenic mutation supports Dent disease with normal endosomal acidification. Hum Mutat 39:1139-1149.

Bogdanović R, Draaken M, Toromanović A, Dordević M, Stajić N, Ludwig M. 2010. A novel CLCN5 mutation in a boy with Bartter-like syndrome and partial growth hormone deficiency. Pediatr Nephrol 25:2363-2368.

Bowers KJ, Chow DE, Xu H, Dror RO, Eastwood MP, Gregersen BA, Klepeis JL, Kolossvary I, Moraes MA, Sacerdoti FD, Salmon JK, Shan Y, et al. 2006. Scalable Algorithms for Molecular Dynamics Simulations on Commodity Clusters. In: SC '06: Proceedings of the 2006 ACM/IEEE Conference on Supercomputing,.

Chang M-H, Brown MR, Liu Y, Gainullin VG, Harris PC, Romero MF, Lieske JC. 2020. Cland $\mathrm{H}+$ coupling properties and subcellular localizations of wildtype and disease-associated variants of the voltage-gated $\mathrm{Cl}-/ \mathrm{H}+$ exchanger ClC-5. J Biol Chem 295:1464-1473.

Chavan TS, Cheng RC, Jiang T, Mathews II, Stein RA, Koehl A, Mchaourab HS, Tajkhorshid E, Maduke M. 2020. A CLC-ec1 mutant reveals global conformational change and suggests a unifying mechanism for the CLC Cl-/H+ transport cycle. Elife 9:e54479.

Chen T-Y, Hwang T-C. 2008. CLC-0 and CFTR: chloride channels evolved from transporters. Physiol Rev 88:351-387.

D’Antonio C, Molinski S, Ahmadi S, Huan LJ, Wellhauser L, Bear CE. 2013.

Conformational defects underlie proteasomal degradation of Dent's disease-causing mutants of ClC-5. The Biochemical journal 452:391-400.

Devuyst O, Christie PT, Courtoy PJ, Beauwens R, Thakker RV. 1999. Intra-renal and subcellular distribution of the human chloride channel, CLC-5, reveals a pathophysiological basis for Dent's disease. Human molecular genetics 8:247-57.

Dutzler R, Campbell EB, Cadene M, Chait BT, MacKinnon R. 2002. X-ray structure of a ClC chloride channel at 3.0 A reveals the molecular basis of anion selectivity. Nature 415:287-94. 
Dutzler R, Campbell EB, MacKinnon R. 2003. Gating the selectivity filter in ClC chloride channels. Science 300:108-12.

Feng L, Campbell EB, Hsiung Y, MacKinnon R. 2010. Structure of a eukaryotic CLC transporter defines an intermediate state in the transport cycle. Science 330:635-41.

Gorvin CM, Wilmer MJ, Piret SE, Harding B, Heuvel LP van den, Wrong O, Jat PS, Lippiat JD, Levtchenko EN, Thakker RV. 2013. Receptor-mediated endocytosis and endosomal acidification is impaired in proximal tubule epithelial cells of Dent disease patients. Proceedings of the National Academy of Sciences of the United States of America 110:70149.

Grand T, L'Hoste S, Mordasini D, Defontaine N, Keck M, Pennaforte T, Genete M, Laghmani K, Teulon J, Lourdel S. 2011. Heterogeneity in the processing of CLCN5 mutants related to Dent disease. Human mutation 32:476-83.

Grand T, Mordasini D, L'Hoste S, Pennaforte T, Genete M, Biyeyeme MJ, Vargas-Poussou R, Blanchard A, Teulon J, Lourdel S. 2009. Novel CLCN5 mutations in patients with Dent's disease result in altered ion currents or impaired exchanger processing. Kidney international 76:999-1005.

Guerriero CJ, Brodsky JL. 2012. The delicate balance between secreted protein folding and endoplasmic reticulum-associated degradation in human physiology. Physiol Rev 92:537576.

Gunther W, Luchow A, Cluzeaud F, Vandewalle A, Jentsch TJ. 1998. ClC-5, the chloride channel mutated in Dent's disease, colocalizes with the proton pump in endocytotically active kidney cells. Proceedings of the National Academy of Sciences of the United States of America 95:8075-80.

Gunther W, Piwon N, Jentsch TJ. 2003. The ClC-5 chloride channel knock-out mouse - an animal model for Dent's disease. Pflugers Arch 445:456-62.

Hichri H, Rendu J, Monnier N, Coutton C, Dorseuil O, Poussou RV, Baujat G, Blanchard A, Nobili F, Ranchin B, Remesy M, Salomon R, et al. 2011. From Lowe syndrome to Dent disease: correlations between mutations of the OCRL1 gene and clinical and biochemical phenotypes. Hum Mutat 32:379-388.

Hoopes RR Jr, Raja KM, Koich A, Hueber P, Reid R, Knohl SJ, Scheinman SJ. 2004. Evidence for genetic heterogeneity in Dent's disease. Kidney international 65:1615-20.

Hoopes RR Jr, Shrimpton AE, Knohl SJ, Hueber P, Hoppe B, Matyus J, Simckes A, Tasic V, Toenshoff B, Suchy SF, Nussbaum RL, Scheinman SJ. 2005. Dent Disease with mutations in OCRL1. American journal of human genetics 76:260-7.

Hryciw DH, Ekberg J, Pollock CA, Poronnik P. 2006. ClC-5: a chloride channel with multiple roles in renal tubular albumin uptake. The international journal of biochemistry \& cell biology 38:1036-42.

Hryciw DH, Kruger WA, Briffa JF, Slattery C, Bolithon A, Lee A, Poronnik P. 2012. Sgk-1 is a positive regulator of constitutive albumin uptake in renal proximal tubule cells. Cell Physiol Biochem 30:1215-1226. 
Hryciw DH, Wang Y, Devuyst O, Pollock CA, Poronnik P, Guggino WB. 2003. Cofilin interacts with $\mathrm{ClC}-5$ and regulates albumin uptake in proximal tubule cell lines. The Journal of biological chemistry 278:40169-76.

Humphrey W, Dalke A, Schulten K. 1996. VMD : visual molecular dynamics. J. Mol. Graph. Journal of Molecular Graphics and Modelling 14:33-38.

Jentsch TJ, Pusch M. 2018. CLC Chloride Channels and Transporters: Structure, Function, Physiology, and Disease. Physiol Rev 98:1493-1590.

Kaminski GA, Friesner RA, Tirado-Rives J, Jorgensen WL. 2001. Evaluation and Reparametrization of the OPLS-AA Force Field for Proteins via Comparison with Accurate Quantum Chemical Calculations on Peptides. J Phys Chem B 105:6474-6487.

Lee A, Slattery C, Nikolic-Paterson DJ, Hryciw DH, Wilk S, Wilk E, Zhang Y, Valova VA, Robinson PJ, Kelly DJ, Poronnik P. 2015. Chloride channel ClC-5 binds to aspartyl aminopeptidase to regulate renal albumin endocytosis. American journal of physiology 308:F784-92.

Lee S, Swanson JMJ, Voth GA. 2016. Multiscale Simulations Reveal Key Aspects of the Proton Transport Mechanism in the ClC-ec1 Antiporter. Biophys J 110:1334-1345.

Lourdel S, Grand T, Burgos J, Gonzalez W, Sepulveda FV, Teulon J. 2012. ClC-5 mutations associated with Dent's disease: a major role of the dimer interface. Pflugers Arch 463:24756.

Maduke M, Miller C, Mindell JA. 2000. A decade of CLC chloride channels: structure, mechanism, and many unsettled questions. Annu Rev Biophys Biomol Struct 29:411-438.

Mansour-Hendili L, Blanchard A, Le Pottier N, Roncelin I, Lourdel S, Treard C, Gonzalez W, Vergara-Jaque A, Morin G, Colin E, Holder-Espinasse M, Bacchetta J, et al. 2015. Mutation Update of the CLCN5 Gene Responsible for Dent Disease 1. Human mutation $36: 743-52$.

Martyna GJ, Tobias DJ, Klein ML. 1994. Constant pressure molecular dynamics algorithms. J Chem Phys 101:4177-4189.

Miller C. 2006. ClC chloride channels viewed through a transporter lens. Nature 440:484489.

Novarino G, Weinert S, Rickheit G, Jentsch TJ. 2010. Endosomal chloride-proton exchange rather than chloride conductance is crucial for renal endocytosis. Science (New York, NY 328:1398-401.

Olsson MHM, Søndergaard CR, Rostkowski M, Jensen JH. 2011. PROPKA3: Consistent Treatment of Internal and Surface Residues in Empirical pKa Predictions. J Chem Theory Comput 7:525-537.

Picollo A, Pusch M. 2005. Chloride/proton antiporter activity of mammalian CLC proteins ClC-4 and ClC-5. Nature 436:420-3.

Piwon N, Gunther W, Schwake M, Bosl MR, Jentsch TJ. 2000. ClC-5 Cl- -channel disruption impairs endocytosis in a mouse model for Dent's disease. Nature 408:369-73. 
Ramos-Trujillo E, Gonzalez-Acosta H, Flores C, Garcia-Nieto V, Guillen E, Gracia S, Vicente C, Espinosa L, Maseda MA, Santos F, Camacho JA, Claverie-Martin F. 2007. A missense mutation in the chloride/proton $\mathrm{ClC}-5$ antiporter gene results in increased expression of an alternative mRNA form that lacks exons 10 and 11. Identification of seven new CLCN5 mutations in patients with Dent's disease. Journal of human genetics 52:255-61.

Reed AA, Loh NY, Terryn S, Lippiat JD, Partridge C, Galvanovskis J, Williams SE, Jouret F, Wu FT, Courtoy PJ, Nesbit MA, Rorsman P, et al. 2010. CLC-5 and KIF3B interact to facilitate CLC-5 plasma membrane expression, endocytosis, and microtubular transport: relevance to pathophysiology of Dent's disease. American journal of physiology 298:F36580 .

Robertson JL, Kolmakova-Partensky L, Miller C. 2010. Design, function and structure of a monomeric ClC transporter. Nature 468:844-847.

Sakamoto H, Sado Y, Naito I, Kwon TH, Inoue S, Endo K, Kawasaki M, Uchida S, Nielsen S, Sasaki S, Marumo F. 1999. Cellular and subcellular immunolocalization of ClC-5 channel in mouse kidney: colocalization with H+-ATPase. The American journal of physiology 277:F957-65.

Satoh N, Yamada H, Yamazaki O, Suzuki M, Nakamura M, Suzuki A, Ashida A, Yamamoto D, Kaku Y, Sekine T, Seki G, Horita S. 2016. A pure chloride channel mutant of CLC-5 causes Dent's disease via insufficient V-ATPase activation. Pflugers Arch 468:1183-1196.

Scheel O, Zdebik AA, Lourdel S, Jentsch TJ. 2005. Voltage-dependent electrogenic chloride/proton exchange by endosomal CLC proteins. Nature 436:424-7.

Sekine T, Komoda F, Miura K, Takita J, Shimadzu M, Matsuyama T, Ashida A, Igarashi T. 2014. Japanese Dent disease has a wider clinical spectrum than Dent disease in Europe/USA: genetic and clinical studies of 86 unrelated patients with low-molecular-weight proteinuria. Nephrol Dial Transplant 29:376-384.

Smith AJ, Reed AA, Loh NY, Thakker RV, Lippiat JD. 2009. Characterization of Dent's disease mutations of CLC-5 reveals a correlation between functional and cell biological consequences and protein structure. American journal of physiology 296:F390-7.

Søndergaard CR, Olsson MHM, Rostkowski M, Jensen JH. 2011. Improved Treatment of Ligands and Coupling Effects in Empirical Calculation and Rationalization of pKa Values. J Chem Theory Comput 7:2284-2295.

Steinmeyer K, Schwappach B, Bens M, Vandewalle A, Jentsch TJ. 1995. Cloning and functional expression of rat CLC-5, a chloride channel related to kidney disease. The Journal of biological chemistry 270:31172-7.

Tang X, Brown MR, Cogal AG, Gauvin D, Harris PC, Lieske JC, Romero MF, Chang M-H. 2016. Functional and transport analyses of CLCN5 genetic changes identified in Dent disease patients. Physiol Rep 4:e12776.

Tosetto E, Ceol M, Mezzabotta F, Ammenti A, Peruzzi L, Caruso MR, Barbano G, Vezzoli G, Colussi G, Vergine G, Giordano M, Glorioso N, et al. 2009. Novel mutations of the CLCN5 gene including a complex allele and A 5' UTR mutation in Dent disease 1. Clin Genet 76:413-416. 
Wang Y, Cai H, Cebotaru L, Hryciw DH, Weinman EJ, Donowitz M, Guggino SE, Guggino WB. 2005. ClC-5: role in endocytosis in the proximal tubule. American journal of physiology 289:F850-62.

Wojciechowski D, Kovalchuk E, Yu L, Tan H, Fahlke C, Stölting G, Alekov AK. 2018. Barttin Regulates the Subcellular Localization and Posttranslational Modification of Human Cl-/H+ Antiporter ClC-5. Front Physiol 9:1490.

Wu F, Roche P, Christie PT, Loh NY, Reed AA, Esnouf RM, Thakker RV. 2003. Modeling study of human renal chloride channel (hCLC-5) mutations suggests a structural-functional relationship. Kidney international 63:1426-32.

Zifarelli G, De Stefano S, Zanardi I, Pusch M. 2012. On the Mechanism of Gating Charge Movement of ClC-5, a Human Cl-/H+ Antiporter. Biophys J 102:2060-2069. 


\section{FIGURE LEGENDS}

Figure 1. Electrophysiological characterization of WT and mutant CIC-5 currents in $X$. laevis oocytes. A: Current-voltage relationships obtained from oocytes expressing WT and mutant ClC-5, and from noninjected oocytes in ND96 solution. B: Representative voltageclamp recordings obtained from oocytes expressing WT and mutant $\mathrm{ClC}-5$, and from noninjected oocytes under the same conditions as described in A. WT, oocytes injected with

wild-type ClC-5; NI, noninjected oocytes. C: Summary of current amplitudes at $+100 \mathrm{mV}$ obtained from oocytes expressing WT and mutant ClC-5. D: Summary of the gating charge normalized by the current amplitude at $+100 \mathrm{mV}$ from oocytes expressing WT and mutant ClC-5. Each data point represents the mean \pm SEM for at least eight oocytes (WT, $n=19$; p.Gly261Glu, $n=8$; p.Gly261Arg, $n=10 ;$ p.Leu266Val, $n=8$; p.Glu267Asp, $n=8$; p.Ser270Gly, $n=12$; p.Tyr272Asn, $n=13$; p.Phe273Leu, $n=11$; NI, $n=18)$. * $P<0.05$; **, $P<0.01$; ***, $P<0.001$; between WT and mutant ClC-5.

Figure 2. Immunocytochemical localization of WT and mutant CIC-5 in HEK293T transfected cells. ClC-5 was detected by green fluorescence. Plasma membrane, early endosomes and ER were respectively stained with biotin, EEA1 and calnexin. These organelles were detected by red fluorescence. The yellow fluorescence indicates that the two proteins overlap. Scale bars : $20 \mu \mathrm{m}$.

Figure 3. Western blot analysis of WT and mutant CIC-5 in HEK293T transfected cells. Total cell lysates were isolated from HEK293T cells $48 \mathrm{~h}$ after transfection. $\beta$-actin was used as the loading marker of the samples. A: Immunoblot of WT and mutant ClC-5. B: 
Densitometric analysis of total ClC-5/ $\beta$-actin normalized to WT. Each column represents the mean \pm SEM from 4-9 experiments. \#, complex-glycosylated form of $\mathrm{ClC} 5$; <, coreglycosylated form of ClC-5; C: Densitometric analysis of the complex-glycosylated form of ClC-5 / total ClC-5 normalized to WT. Each column represents the mean \pm SEM from 5 experiments. * $P<0.05$; **, $P<0.01$; ***, $P<0.001$; between WT and mutant ClC-5.

\section{Figure 4. Cycloheximide-chase analysis of WT and mutant ClC-5 in HEK293T} transfected cells. $24 \mathrm{~h}$ post-transfection, HEK293T cells were chased for the indicated times after addition of cycloheximide. $\beta$-actin was used as the loading marker of the total cell lysates. A: Immunoblot of WT and mutant $\mathrm{ClC}-5$ at different time points. B: Densitometric analysis of the immature form $\mathrm{ClC}-5$ was normalized to the density at time $0 . \mathbf{C}$ : Densitometric analysis of the mature form of $\mathrm{ClC}-5$ to the total density at time 0 . Each data point represents the mean \pm SEM of 3-4 values. \#, complex-glycosylated form of ClC5; <, core-glycosylated form of ClC-5.

Figure 5. Degradation pathways of WT and mutant CIC-5 in HEK239T transfected cells. 24 h post-transfection, HEK293T cells were treated with (+) or without (-) the proteasome inhibitor MG132 or the lysosome inhibitor leupeptin. $\beta$-actin was used as the loading marker of the total cell lysates. A: Immunoblot of WT and mutant ClC-5. B: Densitometric analysis of the total abundance of ClC-5 from untreated and treated cells with M132 or leupeptin. Each column represents the mean \pm SEM from 3 experiments. \#, complex-glycosylated form of ClC5; <, core-glycosylated form of ClC-5; *, $P<0.05$ between WT and mutant ClC-5. 
Figure 6. pKa value of the "proton glutamate" residue depending on the CIC-5 mutation. The computed pKa values were plotted as a histogram. The dashed black line represents the average calculated for 100 frames in monomer A.

Figure 7. E268 establishes a water bridge with K174. During MD simulations this salt bridge interaction is only observed in ClC-5 wild-type but not in class 3 mutants. 
Table 1. pKA shift of E268 residue in class 3 mutants. The pKa values of E68 residue were computed along $100 \mathrm{~ns}$ of MD simulations for each system. The pKa model for glutamic acid residues is used as a reference to describe the shift in every system.

\begin{tabular}{|c|c|c|}
\hline pKa of E268 residue & Monomer A & \multirow{2}{*}{ Reference model } \\
\hline WT & $3.43 \pm 1.50$ & \multirow{2}{*}{4.5} \\
\cline { 1 - 2 } p.Leu266Val & $5.27 \pm 0.62$ & \\
\cline { 1 - 2 } p.Ser270Gly & $5.86 \pm 0.56$ & \\
\cline { 1 - 2 } p.Tyr272Asn & $5.78 \pm 0.47$ & \\
\hline p.Phe273Leu & $4.68 \pm 0.58$ & \\
\hline
\end{tabular}


Table 2. Salt bridge between E268 residue and K174 residue in ClC-5 WT and the p.Phe273Leu mutant.

\begin{tabular}{|c|c|c|}
\hline E268-K174 & WT & p.Phe273Leu \\
\hline & Chain A & Chain A \\
\hline $\begin{array}{c}\text { \% Permanency } \\
\text { (During MD } \\
\text { simulations) }\end{array}$ & 2,3 & 5 \\
\hline
\end{tabular}


Table 3. Number of water molecules around E268 in WT and class 3 mutants in chain A. The significance levels for all the tests (compared with the WT system) were $p<0.001$.

\begin{tabular}{|c|c|r|}
\hline & Average & $\begin{array}{c}\text { Standard } \\
\text { Deviation }\end{array}$ \\
\hline WT & 5,942116 & 2,091475 \\
\hline p.Glu268Ala & 2,886228 & 1,413164 \\
\hline p.Leu266Val & 5,481038 & 1,571518 \\
\hline p.Ser270Gly & 4,815369 & 1,236654 \\
\hline p.Tyr272Asn & 3,404192 & 0,780188 \\
\hline p.Phe273Leu & 2,562874 & 0,893164 \\
\hline
\end{tabular}


Table 4. Clinical and biochemical abnormalities in probands with Dent syndrome and CLCN5 mutations expressed in vitro.

\begin{tabular}{|c|c|c|c|c|c|c|c|c|c|}
\hline & $F 1-1$ & $F 3$ & D208 & D36 & D237 & D162 & F6-1 & D117 & P374 \\
\hline Age at first symptom (years) & 1 & NA & 13 & 15 & 6 & 0.2 & 6 & 3.3 & NA \\
\hline Circumstances & Failure to thrive & NA & Proteinuria & NA & Rickets & $\begin{array}{c}\text { Fortuitous } \\
\text { discovery of NC }\end{array}$ & NA & NA & NA \\
\hline Failure to thrive & Yes & NA & No & NA & No & No & NA & NA & NA \\
\hline Renal impairment & No & No & Yes & No & No & No & NA & No & NA \\
\hline Nephrocalcinosis (NC) & No & NA & Yes & No & Yes & Yes & NA & NA & NA \\
\hline Nephrolithiasis (NL) & No & NA & Yes & No & No & Yes & NA & No & No \\
\hline Hyperphosphaturia & Yes & NA & No & NA & Yes & Yes & NA & NA & NA \\
\hline Rickets & Yes & NA & No & No & Yes & No & NA & No & Yes \\
\hline Kalemia $(\mathrm{mmol} / \mathrm{L})$ & 2.3 & NA & NA & NA & 3.5 & 3.7 & NA & NA & NA \\
\hline Phosphate (mmol/L) & 0.56 & NA & NA & NA & 0.87 & 1.16 & NA & NA & NA \\
\hline Creatinine $(\mu \mathrm{mol} / \mathrm{L})$ & 28 & NA & NA & 48 & 32 & 26 & NA & NA & NA \\
\hline LMWP & Yes & Yes & Yes & Yes & Yes & Yes & Yes & Yes & Yes \\
\hline $\begin{array}{l}\text { B2microglobuline } \\
\text { (mg/mmol creatinine) }\end{array}$ & 28.6 & NA & NA & NA & NA & NA & NA & NA & NA \\
\hline $\begin{array}{c}\text { B2microglobuline } \\
(\mathrm{mg} / \mathrm{L})\end{array}$ & NA & NA & NA & 16 & NA & 51.5 & NA & NA & 46.8 \\
\hline $\begin{array}{l}\text { Albumin }(\mathrm{mg} / \mathrm{mmol} \\
\text { creatinine })\end{array}$ & NA & NA & NA & NA & NA & 117 & NA & NA & NA \\
\hline $\begin{array}{c}\text { Calciuria }(\mathrm{mmol} / \mathrm{mmol} \\
\text { creatinine })\end{array}$ & NA & NA & NA & 0.56 & 1.49 & 2.21 & NA & NA & NA \\
\hline Calciuria $(\mathrm{mg} / \mathrm{kg} / \mathrm{d})$ & 12 & NA & NA & 5.1 & NA & NA & NA & NA & 7 \\
\hline Aminoaciduria & No & NA & NA & NA & NA & Yes & NA & NA & NA \\
\hline Glycosuria (mmol/L) & No & NA & No & NA & Yes & 0.2 & NA & NA & NA \\
\hline
\end{tabular}




\begin{tabular}{|c|c|c|c|c|c|c|c|c|c|}
\hline Hyperuricosuria (FE) & Yes & NA & Yes & NA & NA & NA & NA & NA & NA \\
\hline Polyuria & Yes & NA & NA & NA & NA & Yes & NA & NA & NA \\
\hline Country & Serbia & Italy & USA & Japan & North Africa & France & USA & Japan & Spain \\
\hline Mutation & $\begin{array}{l}\text { c. } 782 \mathrm{G}>\mathrm{A} \text {, } \\
\text { p.Gly261Glu }\end{array}$ & $\begin{array}{l}\text { c.781G>A, } \\
\text { p.Gly261Arg }\end{array}$ & $\begin{array}{c}\text { c.781G>A, } \\
\text { p.Gly261Arg }\end{array}$ & $\begin{array}{l}\text { c. } 796 \mathrm{C}>\mathrm{G}, \\
\text { p.Leu266Val }\end{array}$ & $\begin{array}{l}\text { c.799G }>\text { A, } \\
\text { p.Glu267Lys }\end{array}$ & $\begin{array}{c}\text { c. } 801 \mathrm{~A}>\mathrm{C} \\
\text { p.Glu267Asp }\end{array}$ & $\begin{array}{l}\text { c.808A>G, } \\
\text { p.Ser270Gly }\end{array}$ & $\begin{array}{l}\text { c. } 814 \mathrm{~T}>\mathrm{A}, \\
\text { p.Tyr272Asn }\end{array}$ & $\begin{array}{c}\text { c. } 817 \mathrm{~T}>\mathrm{C} \\
\text { p.Phe273Leu }\end{array}$ \\
\hline Reference & Bogdanovic 2010 & Tosetto 2009 & $\begin{array}{l}\text { Mansour-Hendili } \\
2015\end{array}$ & $\begin{array}{l}\text { Sekine } 2014 \\
\text { Ashida } 2014\end{array}$ & Ashton 2018 & $\begin{array}{c}\text { Mansour-Hendili } \\
2015\end{array}$ & Hoopes 2004 & Sekine 2014 & $\begin{array}{c}\text { Ramos Trujillo } \\
2007\end{array}$ \\
\hline
\end{tabular}


A

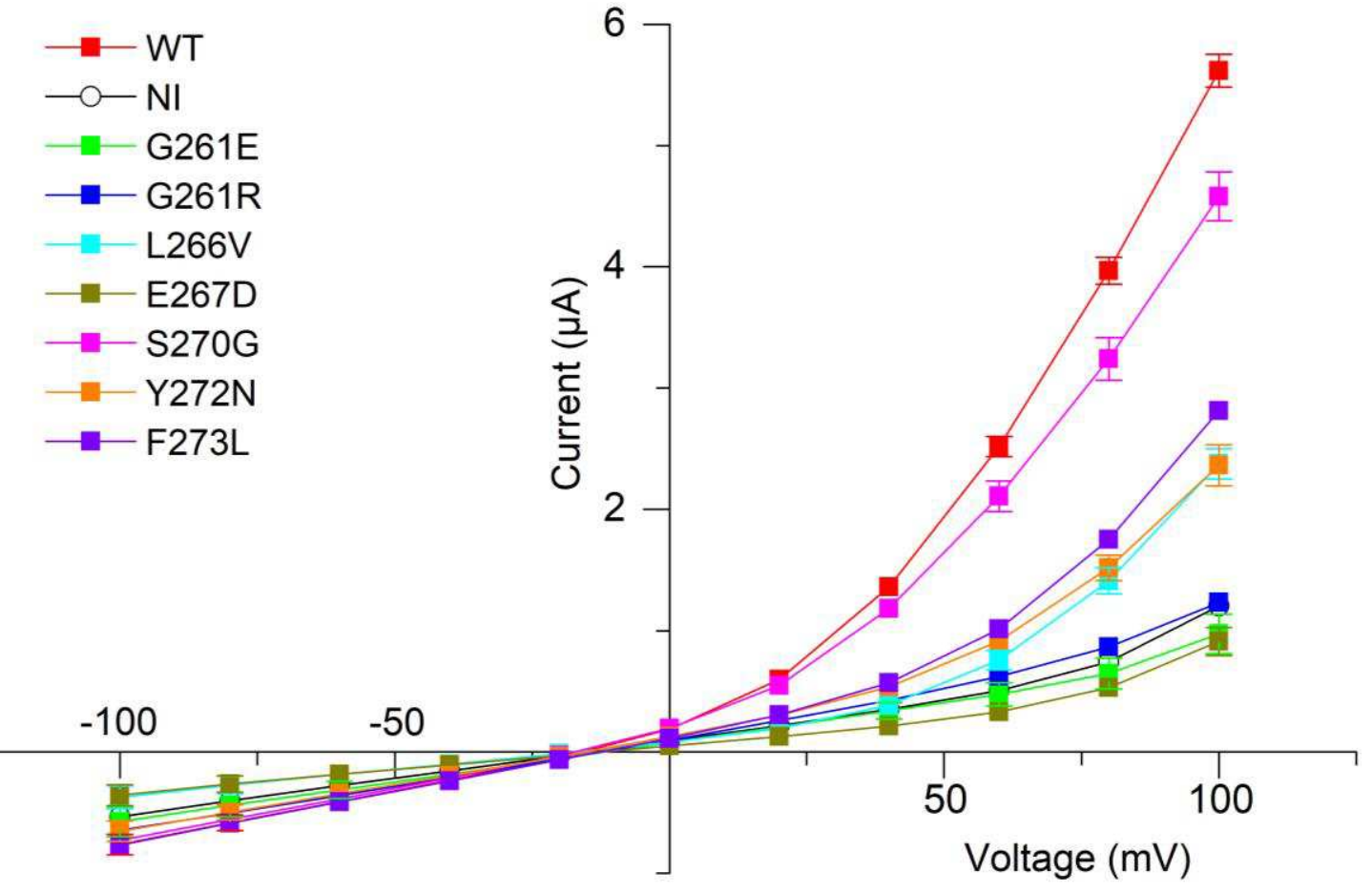

C

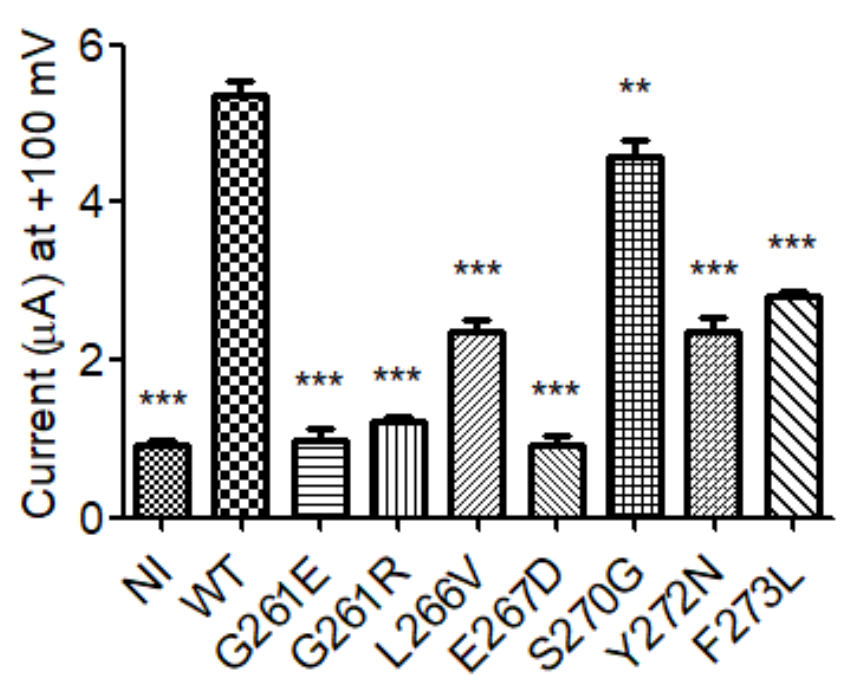

B
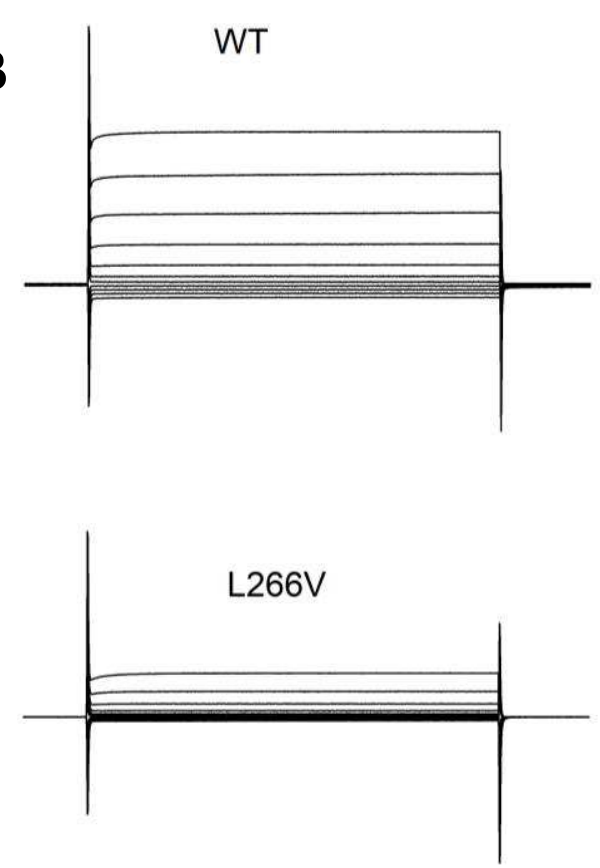

$3 \mu \mathrm{A}$
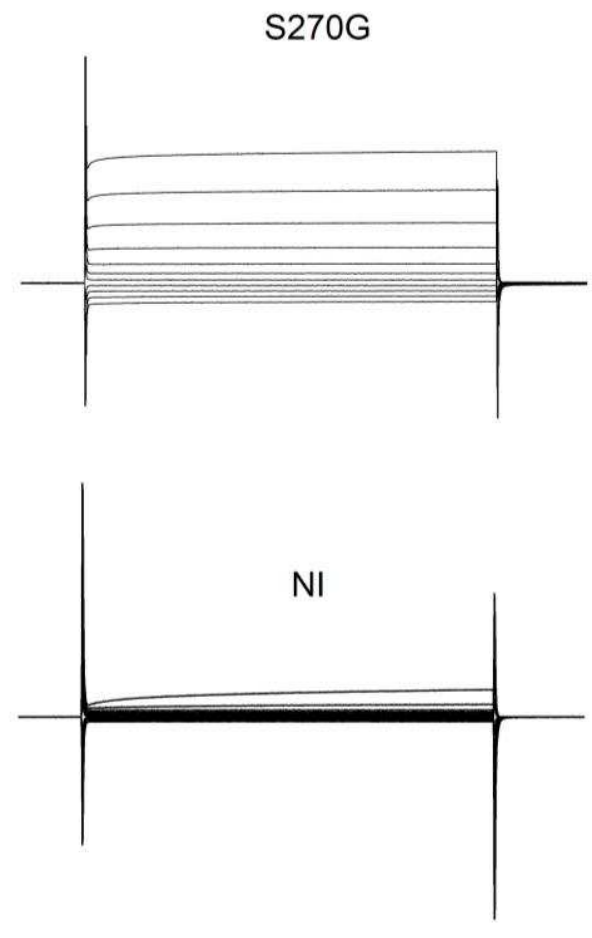

$0.2 \mathrm{~s}$

D

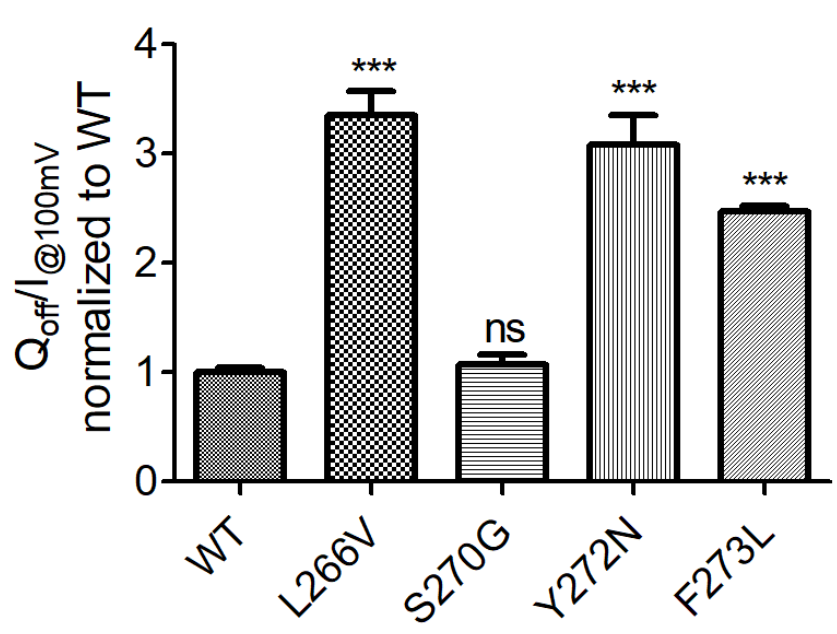

Figure 1 


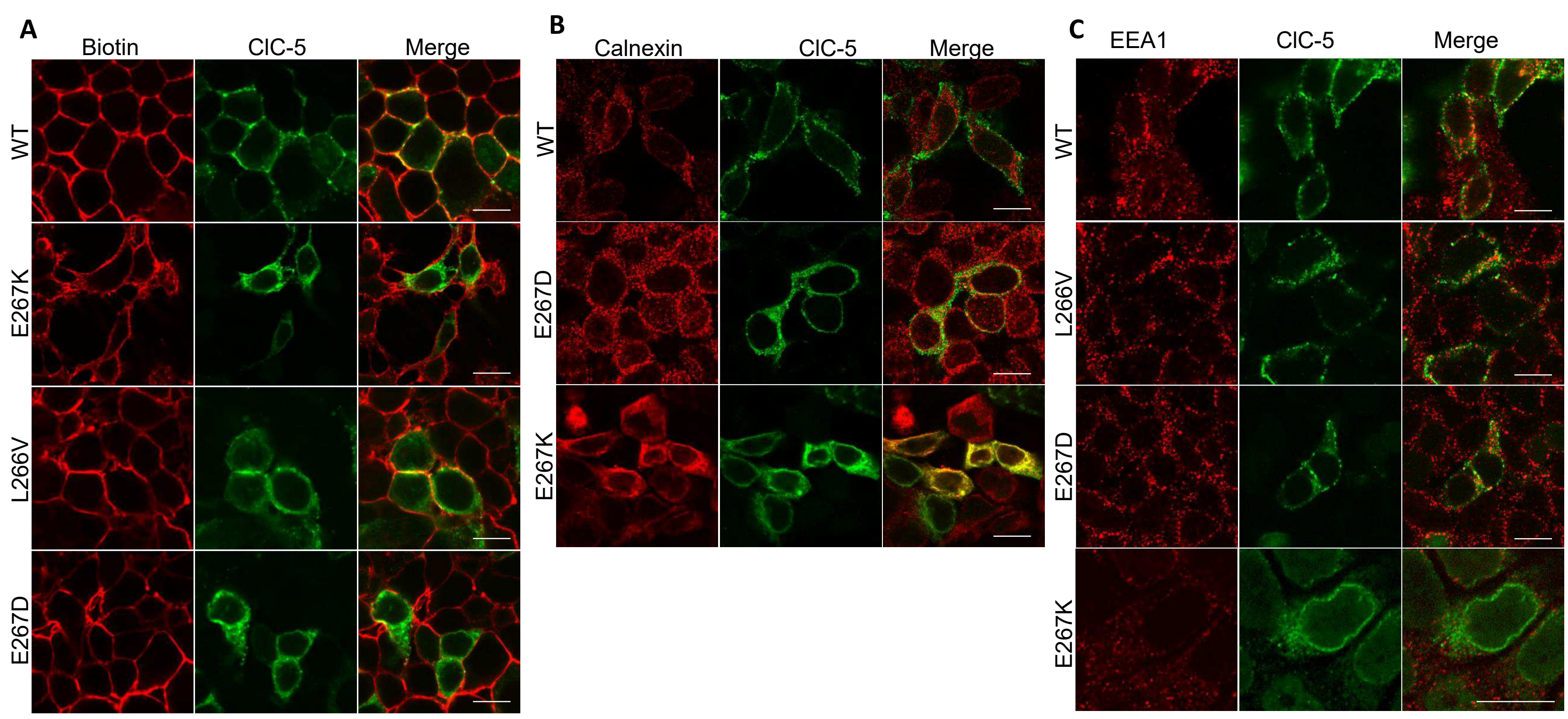

Figure 2 
A

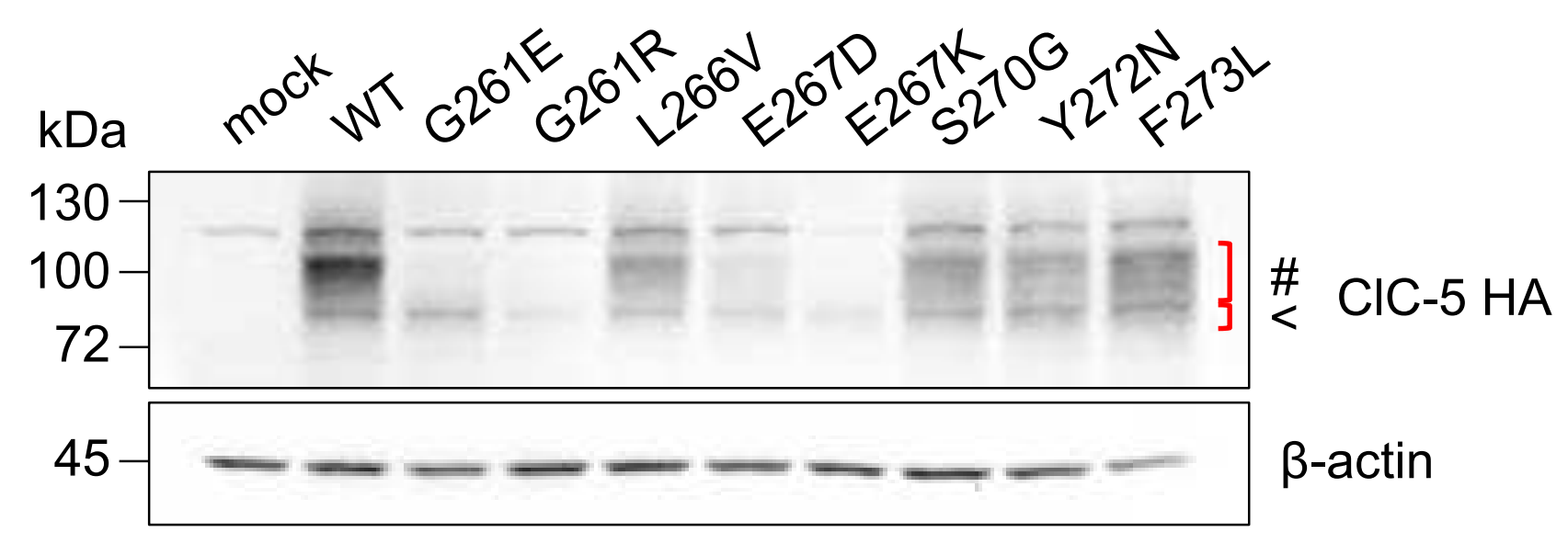

B

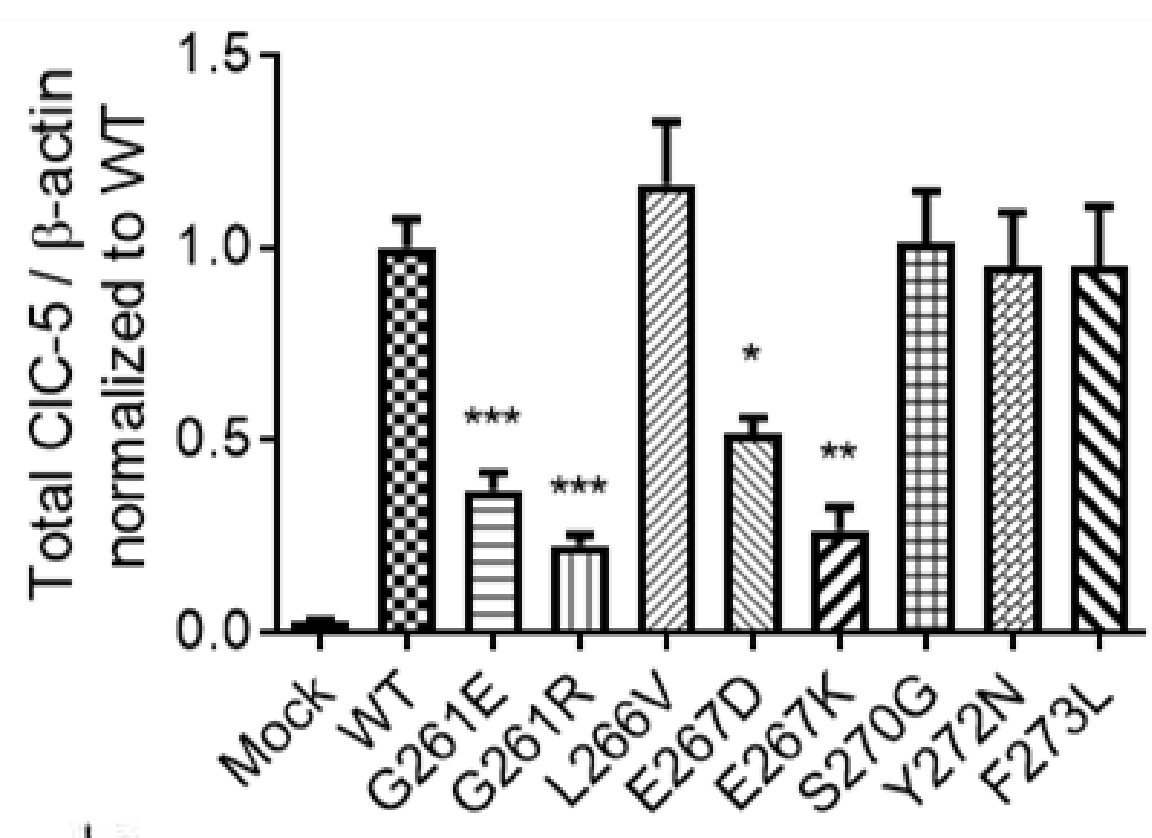

C $E 5$

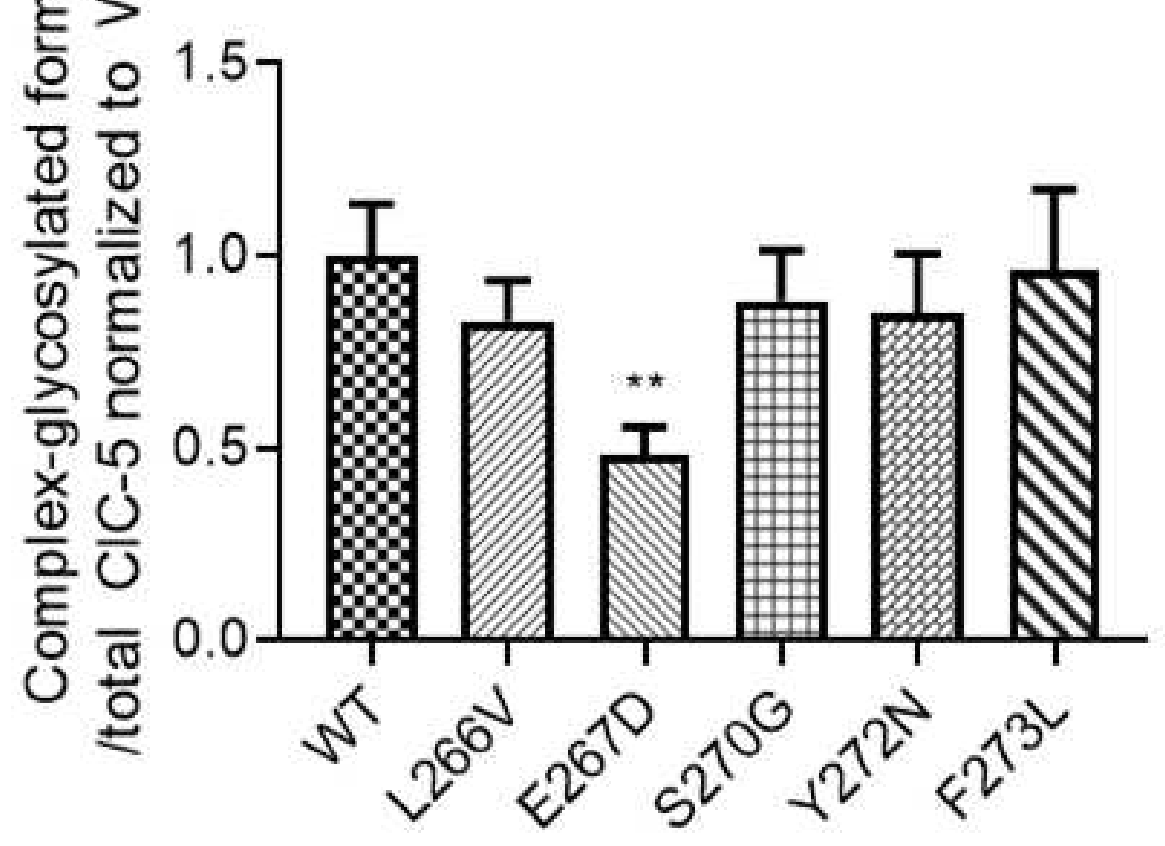

Figure 3 
A

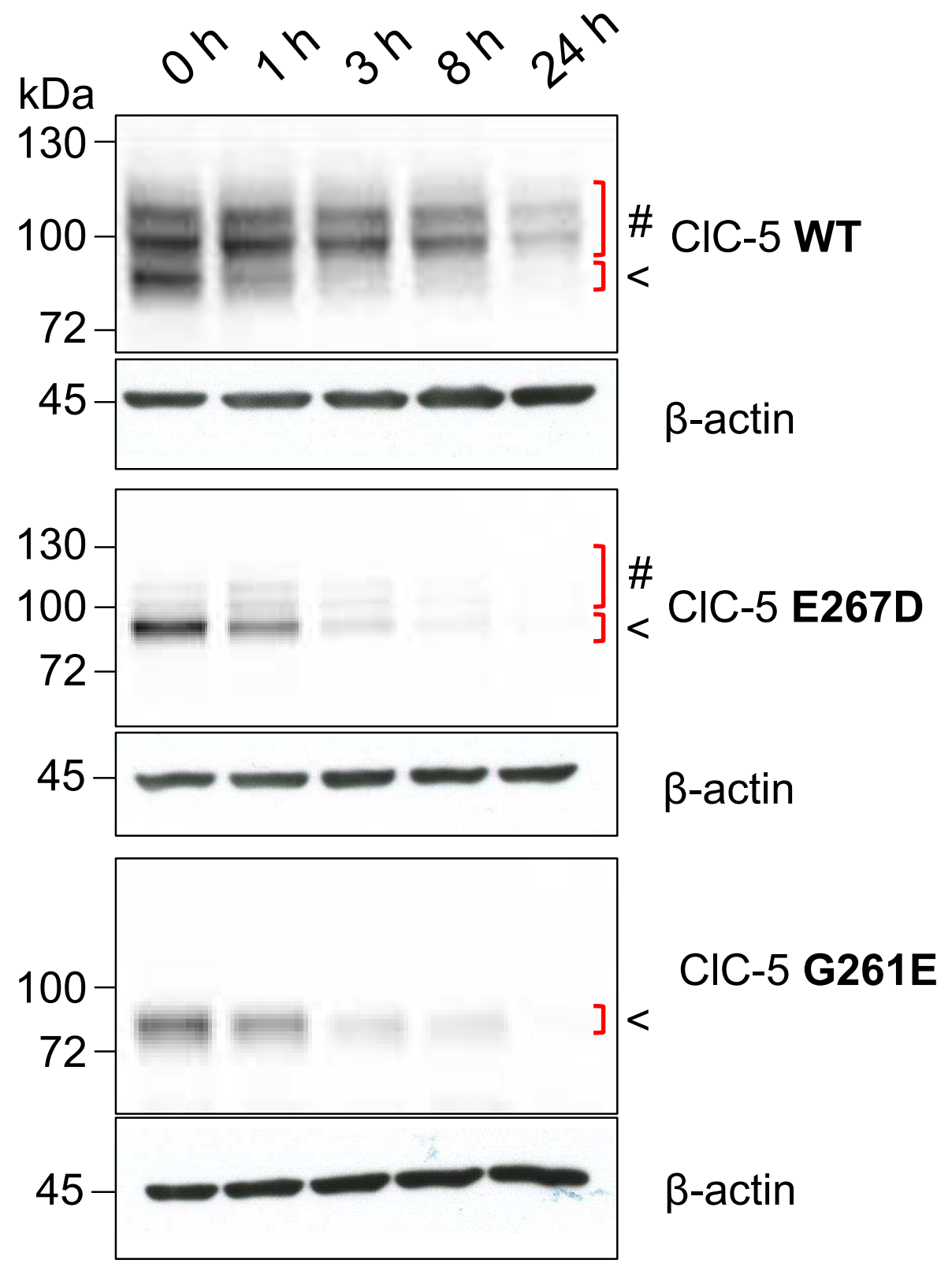

B

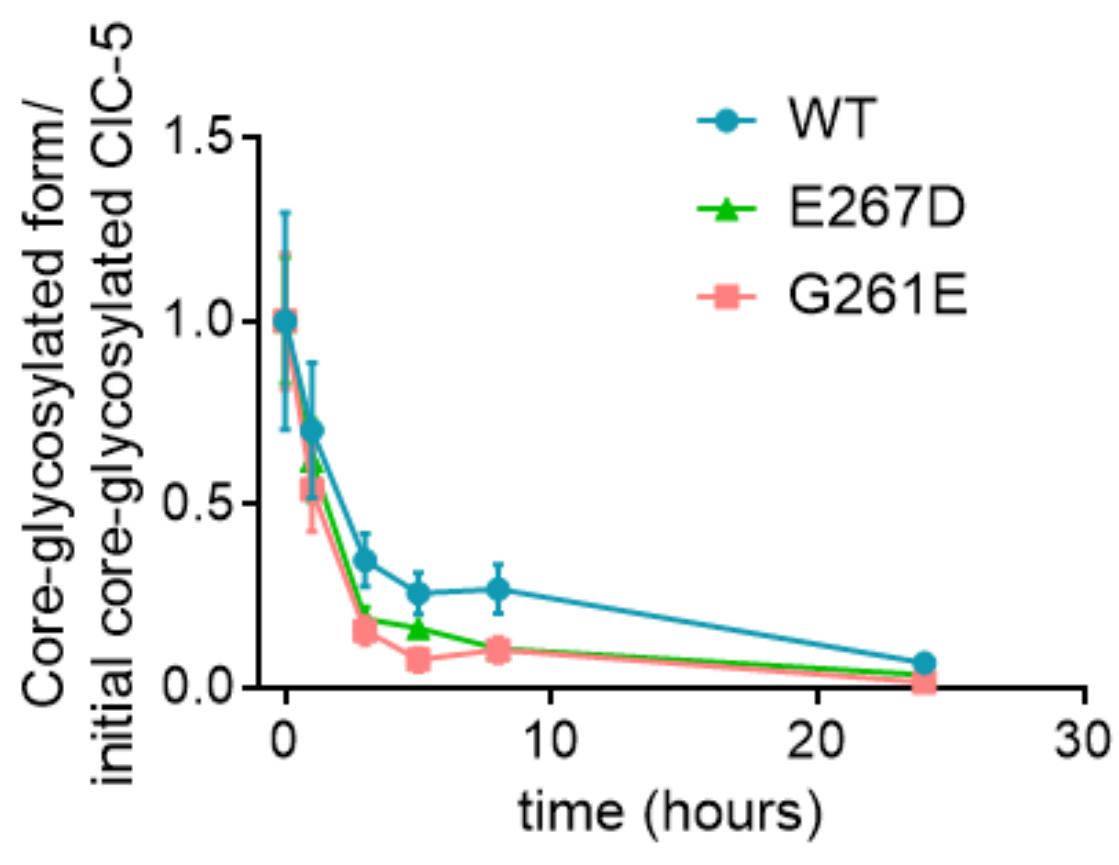

C

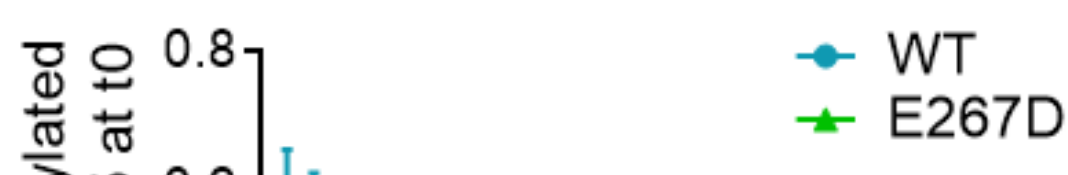

Figure 4

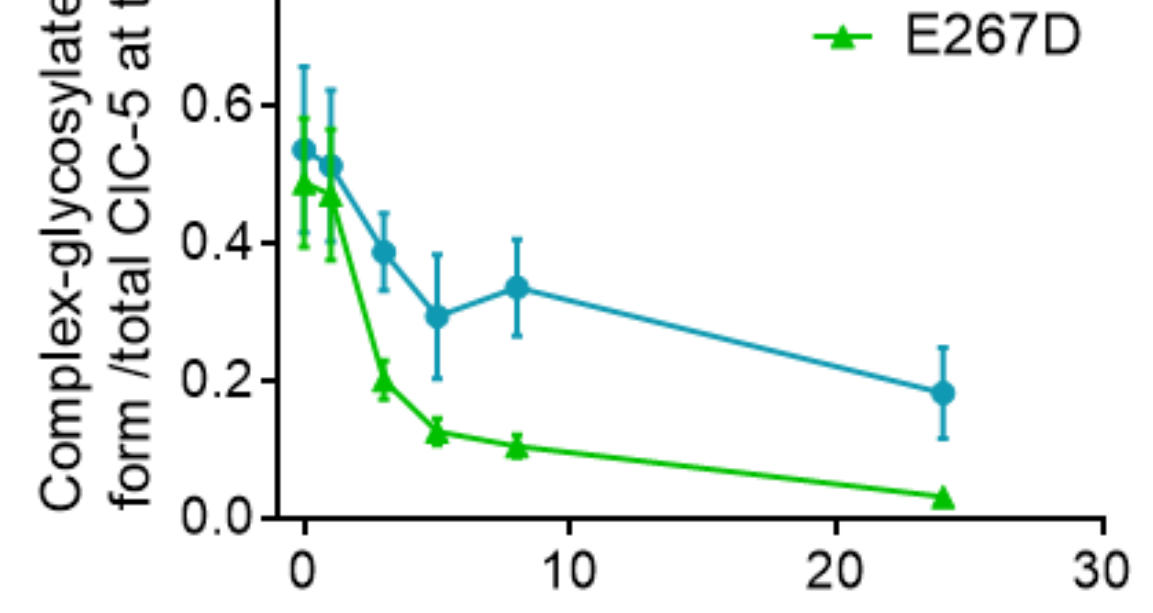

time (hours) 
A

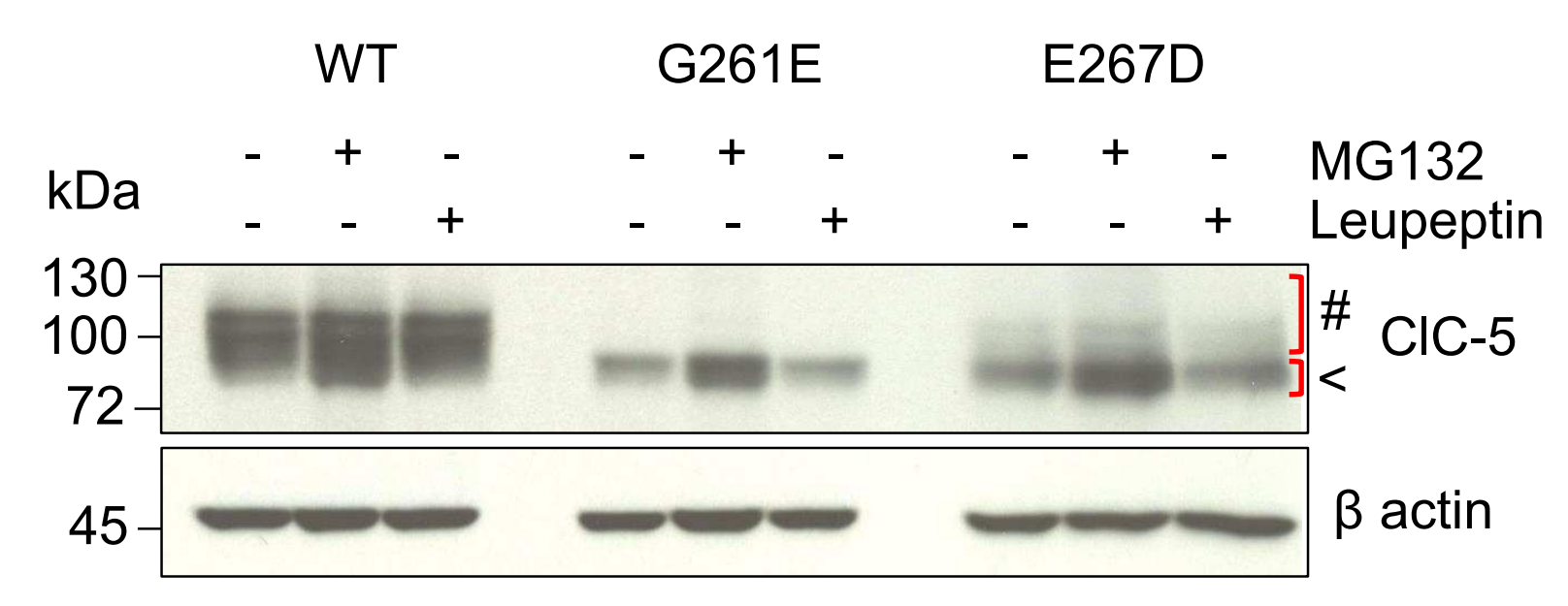

B

$\square$ No treatment

$\square$ MG-132

$\square$ Leupeptin

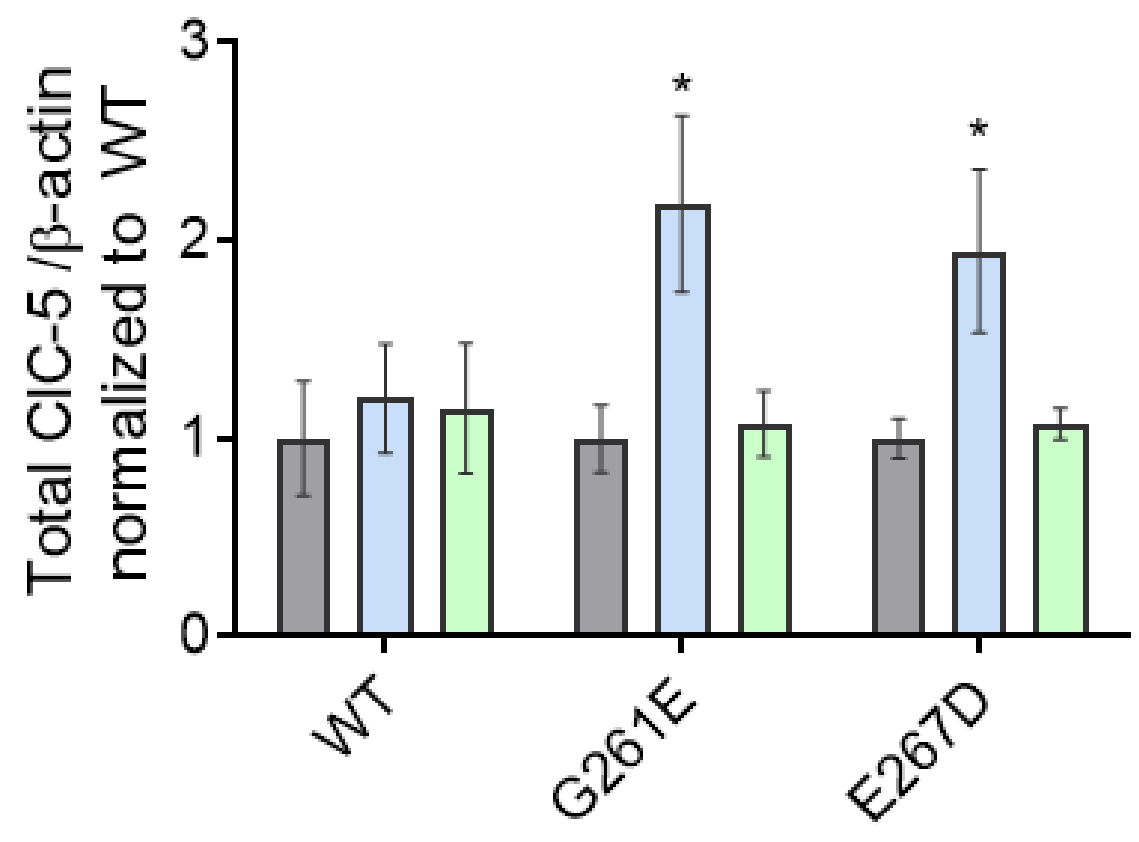

Figure 5 
WT

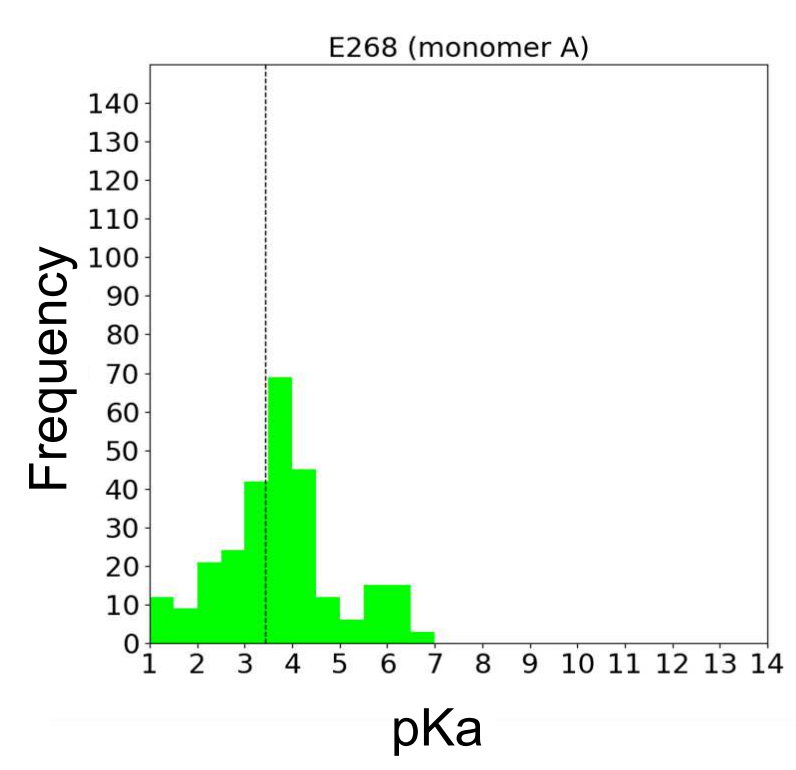

L266V

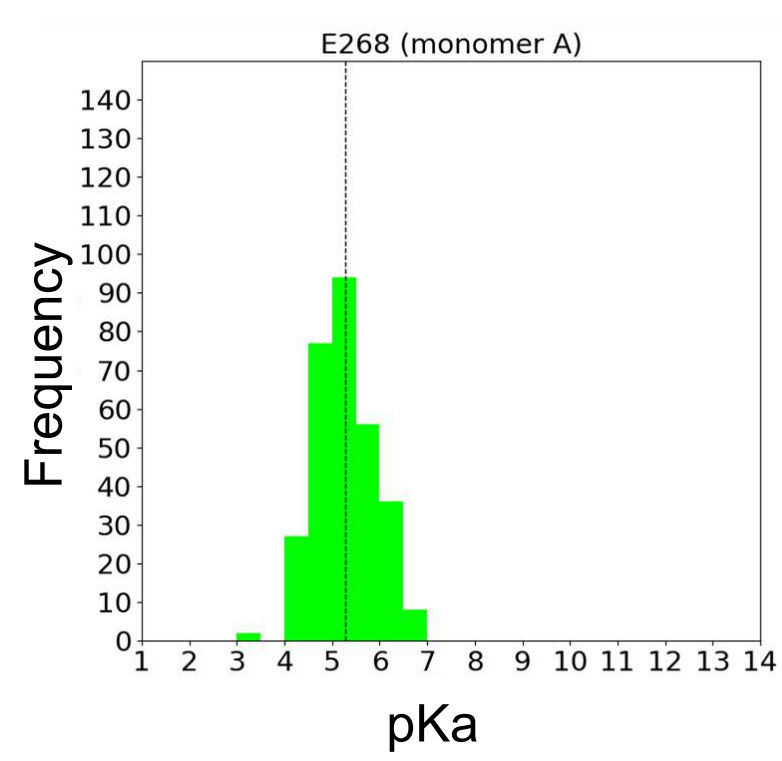

S270G

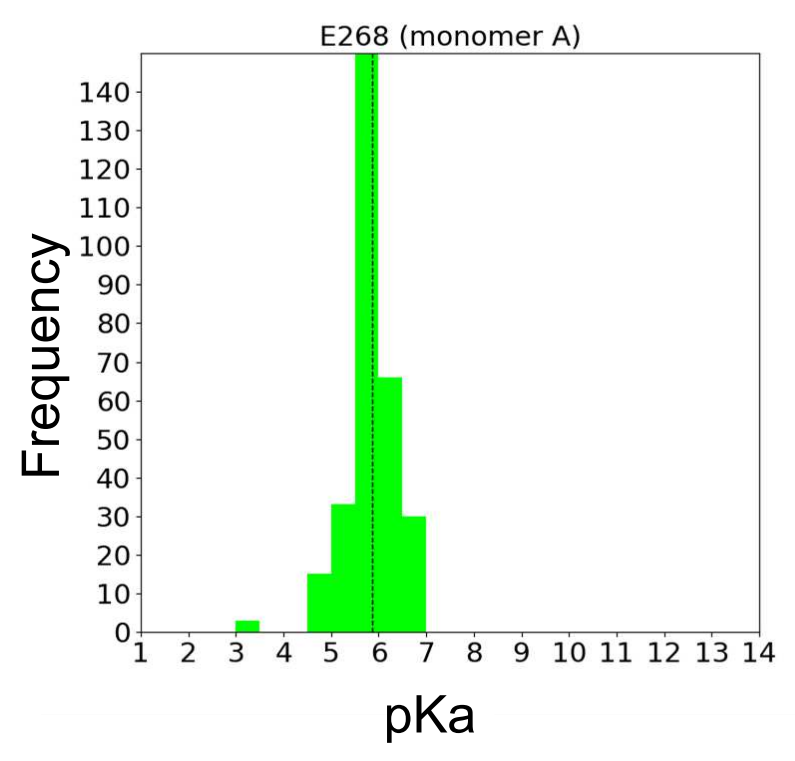

\section{Y272N}

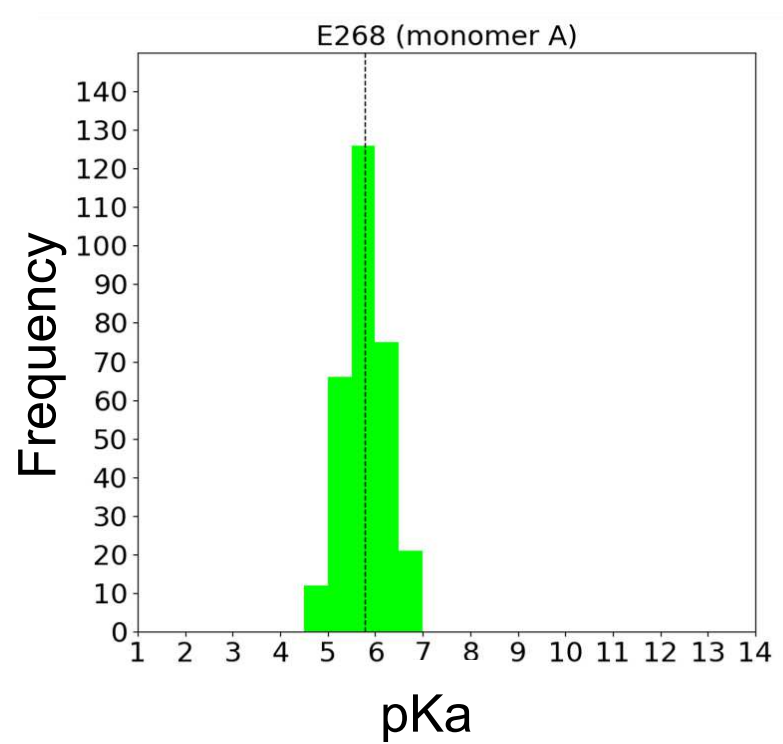

\section{F273L}

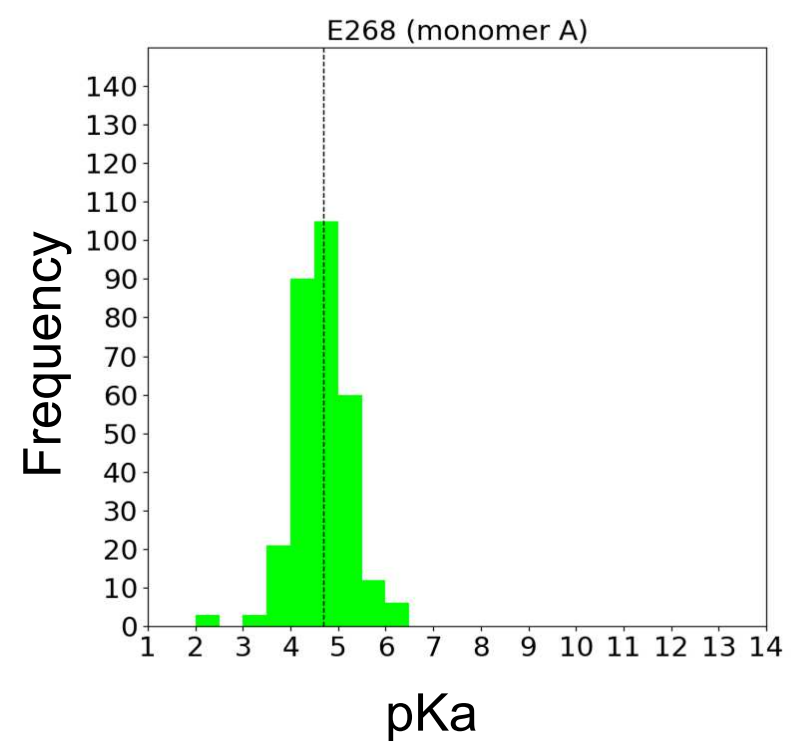

Figure 6 


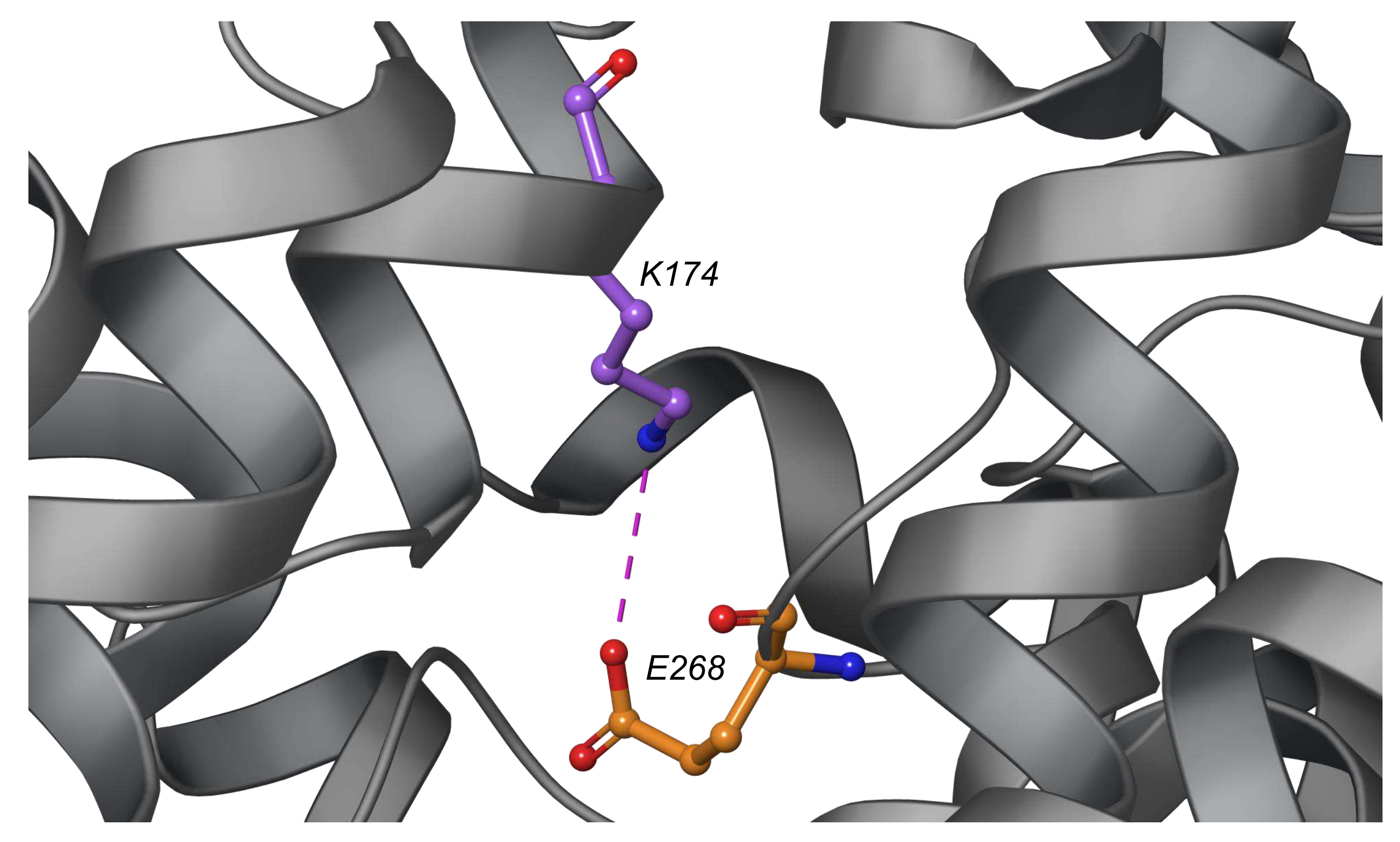

Figure 7 
Supp. Figure S1 : Immunocytochemical localization of WT and mutant CIC-5 in HEK293T transfected cells. CIC-5 was detected by green fluorescence. Plasma membrane, early endosomes and ER were respectively stained with biotin, EEA1 and calnexin. These organelles were detected by red fluorescence. The yellow fluorescence indicates that the two proteins overlap. Scale bars : $20 \mu \mathrm{m}$.
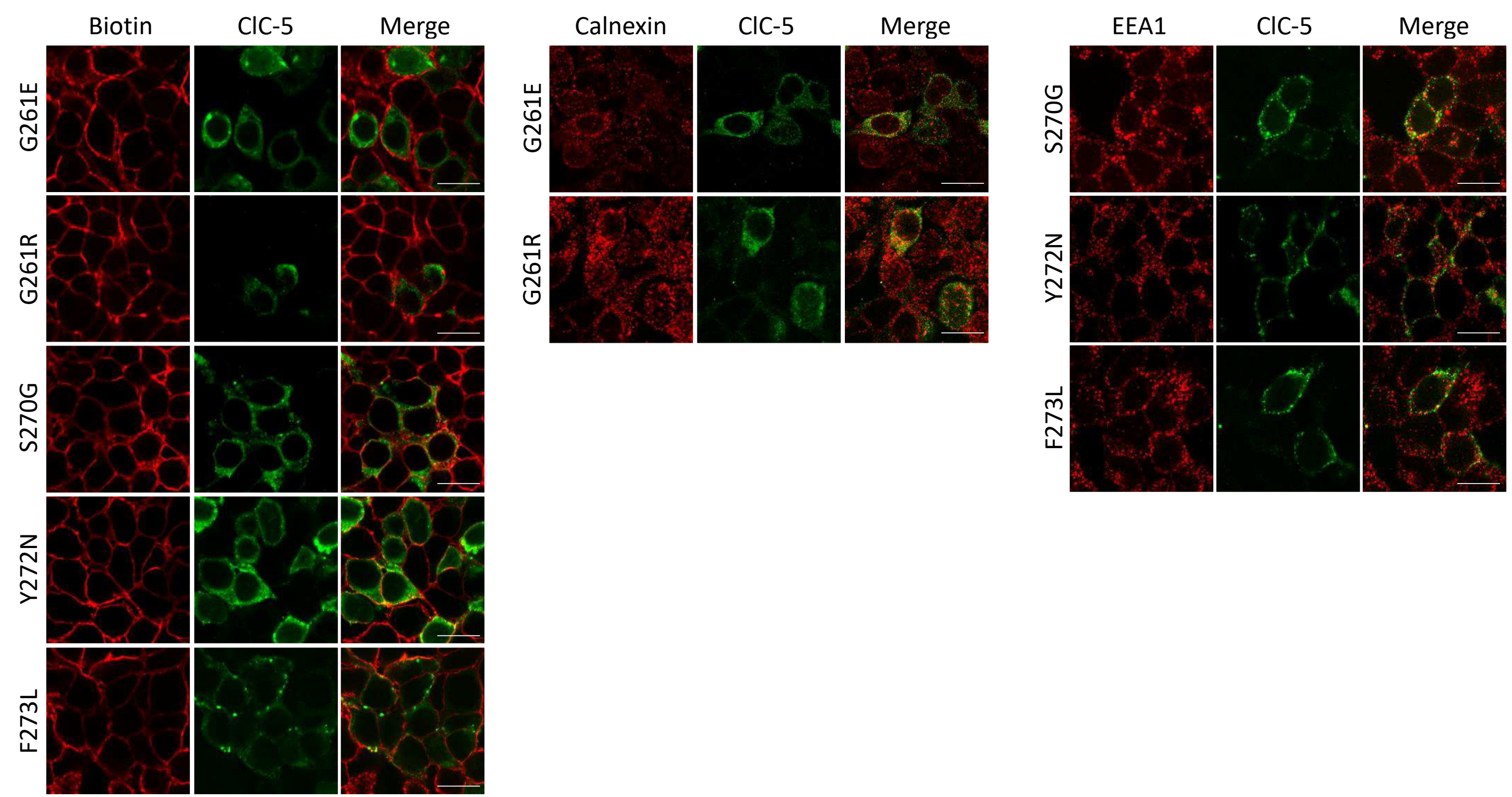
Supp. Figure S2 : Root Mean Square Deviation (RMSD) of backbone in wild type and mutants CIC-5 channels during molecular dynamics (MD) simulations.

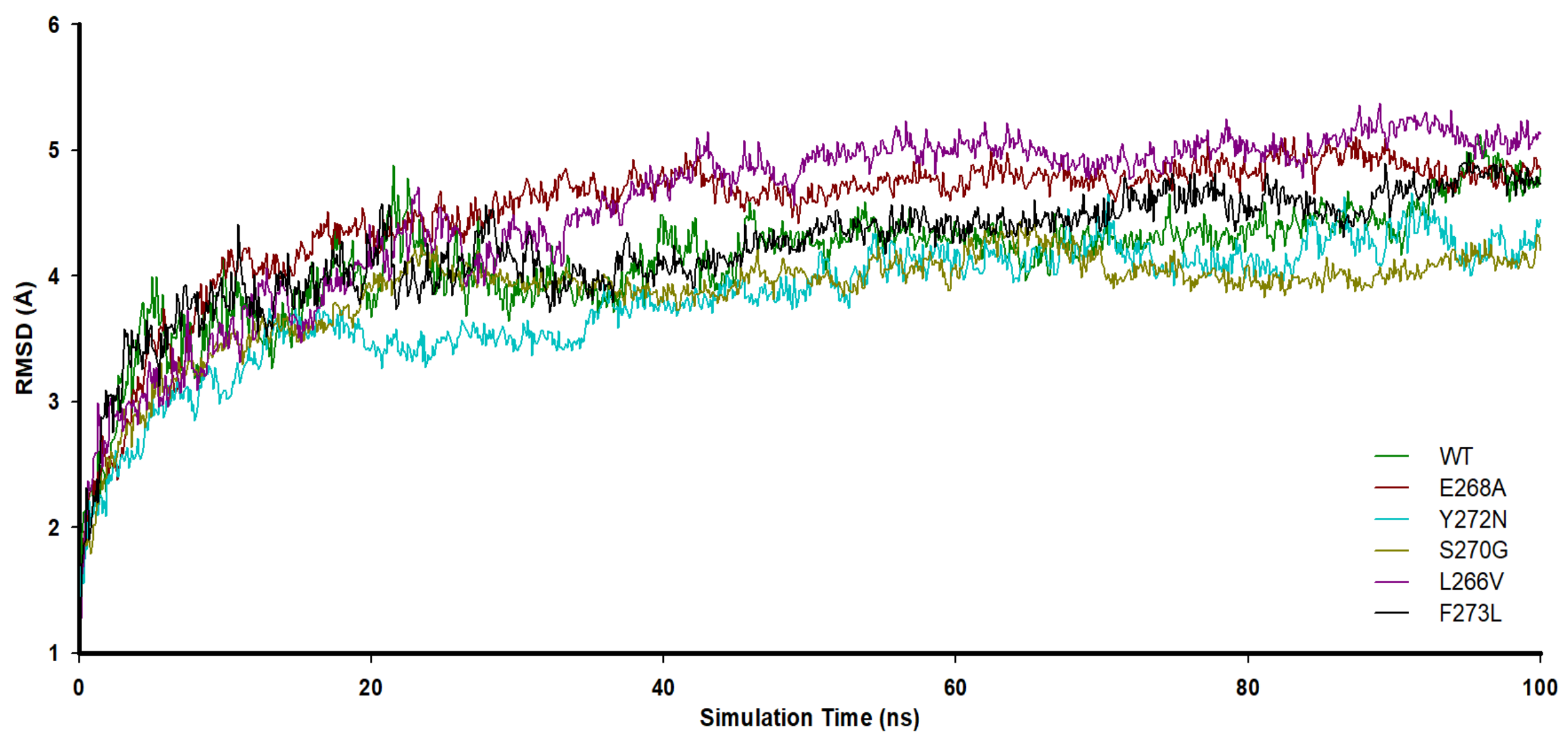


Supp. Figure S3 : Analysis of clinical parameters depending on the class of mutation. A: Age at first symptoms and Low molecular weight proteinuria ( $\beta$-2microglobuline) B: Renal function (Glomerular filtration rate depending on age) of Dent 1 patients according to the class of missense mutation. The red points correspond to patients harboring mutant in the "proton glutamate" region (quantitative parameters).

- Class 1

A

Age at first symptoms

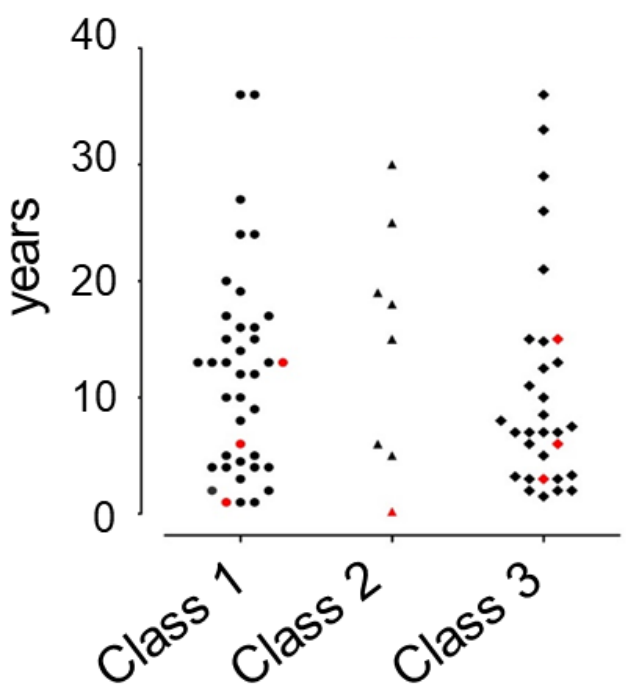

B

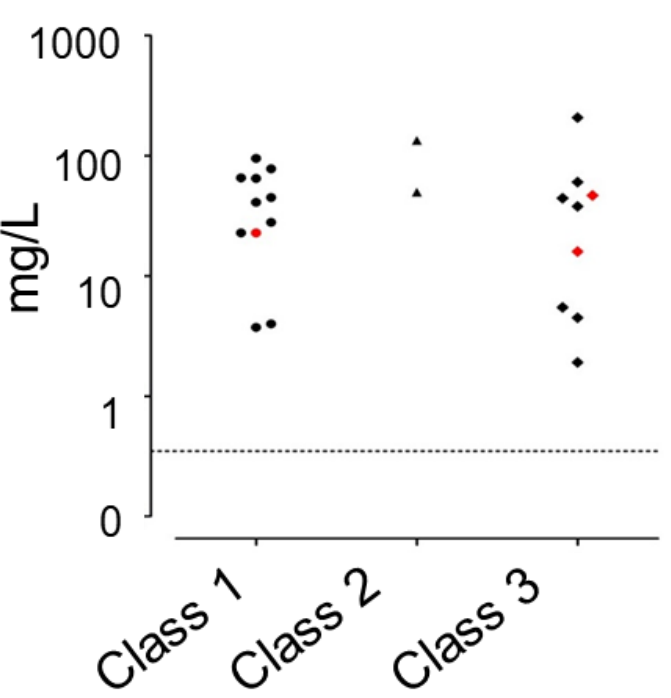

- Class 2

- Class 3

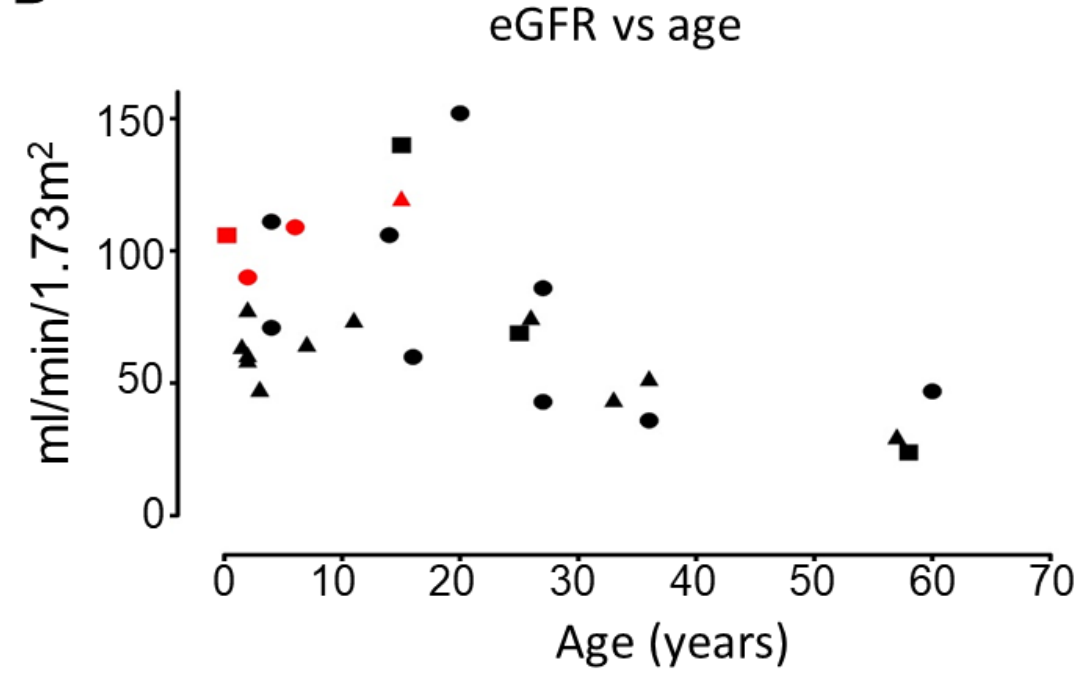


Supp. Table S2. CLCN5 mutations characterized in vitro and their classification.

\begin{tabular}{|c|c|c|c|}
\hline $\begin{array}{l}\text { Class of } \\
\text { mutant }\end{array}$ & $\begin{array}{l}\text { Nomenclature } \\
\text { nucleotide } \\
\text { (cDNA) }\end{array}$ & $\begin{array}{l}\text { Nomenclature } \\
\text { protein }\end{array}$ & Reference \\
\hline \multirow{22}{*}{ Class 1} & c.302G>A & p.Cys101Tyr & (Lee et al., 2009) \\
\hline & c. $536 \mathrm{G}>\mathrm{A}$ & p.Gly179Asp & (Grand et al., 2009) \\
\hline & c. $599 \mathrm{~T}>\mathrm{G}$ & p.Leu200Arg & $\begin{array}{l}\text { (Wrong et al., 1994; Lloyd et al., 1996; Grand et } \\
\text { al., 2009) }\end{array}$ \\
\hline & c. $608 \mathrm{C}>\mathrm{T}$ & p.Ser203Leu & $\begin{array}{l}\text { (Grand et al., 2009; Park et al., 2014; Sekine et } \\
\text { al., 2014) }\end{array}$ \\
\hline & c.655T > C & p.Cys219Arg & (Ramos-Trujillo et al., 2007; Grand et al., 2009) \\
\hline & c.661T>C & p.Cys221Arg & $\begin{array}{l}\text { (Hoopes et al., 2004; Ludwig et al., 2005; Grand } \\
\text { et al., 2009) }\end{array}$ \\
\hline & c. $674 \mathrm{~T}>\mathrm{C}$ & c.Leu225Pro & (Ramos-Trujillo et al., 2007; Grand et al., 2011) \\
\hline & c. $716 \mathrm{G}>\mathrm{C}$ & p.Arg239Pro & (Mansour-Hendili et al., 2015) \\
\hline & c. $748 \mathrm{G}>\mathrm{C}$ & p.Gly250Arg & (Mansour-Hendili et al., 2015) \\
\hline & c. $782 \mathrm{G}>\mathrm{A}$ & p.Gly261Glu & (Bogdanović et al., 2010) \\
\hline & c.781G $>A$ & p.Gly261Arg & (Tosetto et al., 2009) \\
\hline & c. $808 \mathrm{~A}>\mathrm{C}$ & p.Ser270Arg & (Igarashi et al., 1998) \\
\hline & c.971T>G & p.Leu324Arg & (Ludwig et al., 2005) \\
\hline & c.997G >A & p.Gly333Arg & (Tanuma et al., 2007) \\
\hline & c. $1020 C>G$ & p.Asn340Lys & (Tosetto et al., 2006) \\
\hline & c.1385G $>\mathrm{T}$ & p.Gly462Val & (Ludwig et al., 2005, 2006) \\
\hline & c. $1406 \mathrm{~T}>\mathrm{C}$ & p.Leu469Pro & (Ludwig et al., 2005; Grand et al., 2009) \\
\hline & c. $1517 G>A$ & p.Gly506Glu & $\begin{array}{l}\text { (Wrong et al., 1994; Lloyd et al., 1996; } \\
\text { Scheinman et al., 2000) }\end{array}$ \\
\hline & c.1537G>A & p.Gly513Arg & (Hoopes et al., 2004; Sekine et al., 2014) \\
\hline & c.1538G>A & p.Gly513Glu & (Akuta et al., 1997) \\
\hline & c. $1546 C>T$ & p.Arg516Trp & $\begin{array}{c}\text { (Akuta et al., 1997; Hoopes et al., 2004; Ludwig } \\
\text { et al., 2005, 2006; Wu et al., 2009; Park et al., } \\
\text { 2014; Sekine et al., 2014; Mansour-Hendili et } \\
\text { al., 2015) }\end{array}$ \\
\hline & c. $1571 \mathrm{~T}>\mathrm{A}$ & p.lle524Lys & $\begin{array}{l}\text { (Takemura et al., 2001; Hoopes et al., 2004; } \\
\text { Ludwig et al., 2005, 2006; Wu et al., 2009; Park } \\
\text { et al., 2014; Sekine et al., 2014; Mansour- } \\
\text { Hendili et al., 2015) }\end{array}$ \\
\hline \multirow{7}{*}{ Class 2} & c. $779 \mathrm{G}>\mathrm{T}$ & p.Gly260Val & (Anglani et al., 2006; Tosetto et al., 2006) \\
\hline & c. $801 \mathrm{~A}>\mathrm{C}$ & p.Glu267Asp & (Mansour-Hendili et al., 2015) \\
\hline & c. $834 \mathrm{G}>\mathrm{C}$ & p.Leu278Phe & (Igarashi et al., 1998; Sekine et al., 2014) \\
\hline & c.1535G>A & p.Gly512Asp & (Tosetto et al., 2009) \\
\hline & c.1581A $>\mathrm{T}$ & p.GLu527Asp & (Lloyd et al., 1997) \\
\hline & c. $1636 A>G$ & p.Lys546Glu & $\begin{array}{c}\text { (Hoopes et al., 2004; Mansour-Hendili et al., } \\
\text { 2015) }\end{array}$ \\
\hline & c.1639T>G & p.Trp547Gly & $\begin{array}{c}\text { (Ramos-Trujillo et al., 2007; Mansour-Hendili et } \\
\text { al., 2015) }\end{array}$ \\
\hline \multirow{3}{*}{ Class 3} & c. $64 \mathrm{~T}>\mathrm{G}$ & p.Trp22Gly & $\begin{array}{c}\text { (Morimoto et al., 1998; Ramos-Trujillo et al., } \\
\text { 2013) }\end{array}$ \\
\hline & c. $632 A>G$ & p.Glu211Gly & (Bignon et al., 2018) \\
\hline & c. $635 G>A$ & p.Gly212Ala & (Grand et al., 2009) \\
\hline
\end{tabular}




\begin{tabular}{|c|c|c|}
\hline c. $731 \mathrm{C}>\mathrm{T}$ & p.Ser244Leu & $\begin{array}{c}\text { (Wrong et al., 1994; Lloyd et al., 1996; Oudet et } \\
\text { al., 1997; Hoopes et al., 1998; Kelleher et al., } \\
\text { 1998; Anglani et al., 2006; Ludwig et al., 2006; } \\
\text { Tosetto et al., 2006; Blanchard et al., 2008; Wu } \\
\text { et al., 2009; Zhu et al., 2010; Samardzic et al., } \\
\text { 2011; Sekine et al., 2014; Mansour-Hendili et } \\
\text { al., 2015) }\end{array}$ \\
\hline c. $796 C>G$ & p.Leu266Val & (Ashida et al., 2014; Sekine et al., 2014) \\
\hline c. $808 \mathrm{~A}>\mathrm{G}$ & p.Ser270Gly & (Hoopes et al., 2004) \\
\hline c. $815 A>G$ & p.Tyr272Cys & (Tosetto et al., 2006; Sekine et al., 2014) \\
\hline c. $814 \mathrm{~T}>\mathrm{A}$ & p.Tyr272Asn & (Sekine et al., 2014) \\
\hline c. $817 \mathrm{~T}>\mathrm{C}$ & p.Phe273Leu & (Ramos-Trujillo et al., 2007) \\
\hline $\mathrm{c} .817 \mathrm{~T}>\mathrm{C}$ & p.Ser520Pro & (Wrong et al., 1994; Lloyd et al., 1996) \\
\hline
\end{tabular}

\section{Supplementary references}

Akuta N, Lloyd SE, Igarashi T, Shiraga H, Matsuyama T, Yokoro S, Cox JP, Thakker RV. 1997. Mutations of CLCN5 in Japanese children with idiopathic low molecular weight proteinuria, hypercalciuria and nephrocalcinosis. Kidney international 52:911-6.

Anglani F, Bernich P, Tosetto E, Cara M, Lupo A, Nalesso F, D’Angelo A, Gambaro G. 2006. Family history may be misleading in the diagnosis of Dent's disease. Urological research 34:61-3.

Ashida A, Yamamoto D, Nakakura H, Shirasu A, Matsumura H, Sekine T, Igarashi T, Tamai H. 2014. Molecular effect of a novel missense mutation, L266V, on function of ClC-5 protein in a Japanese patient with Dent's disease. Clin Nephrol 82:58-61.

Bignon Y, Alekov A, Frachon N, Lahuna O, Jean-Baptiste Doh-Egueli C, Deschênes G, Vargas-Poussou R, Lourdel S. 2018. A novel CLCN5 pathogenic mutation supports Dent disease with normal endosomal acidification. Hum Mutat 39:1139-1149.

Blanchard A, Vargas-Poussou R, Peyrard S, Mogenet A, Baudouin V, Boudailliez B, Charbit M, Deschesnes G, Ezzhair N, Loirat C, Macher M-A, Niaudet P, et al. 2008. Effect of hydrochlorothiazide on urinary calcium excretion in dent disease: an uncontrolled trial. Am J Kidney Dis 52:1084-1095.

Bogdanović R, Draaken M, Toromanović A, Dordević M, Stajić N, Ludwig M. 2010. A novel CLCN5 mutation in a boy with Bartter-like syndrome and partial growth hormone deficiency. Pediatr Nephrol 25:2363-2368.

Grand T, L'Hoste S, Mordasini D, Defontaine N, Keck M, Pennaforte T, Genete M, Laghmani K, Teulon J, Lourdel S. 2011. Heterogeneity in the processing of CLCN5 mutants related to Dent disease. Human mutation 32:47683.

Grand T, Mordasini D, L'Hoste S, Pennaforte T, Genete M, Biyeyeme MJ, Vargas-Poussou R, Blanchard A, Teulon J, Lourdel S. 2009. Novel CLCN5 mutations in patients with Dent's disease result in altered ion currents or impaired exchanger processing. Kidney international 76:999-1005.

Hoopes RR Jr, Hueber PA, Reid RJ Jr, Braden GL, Goodyer PR, Melnyk AR, Midgley JP, Moel DI, Neu AM, VanWhy SK, Scheinman SJ. 1998. CLCN5 chloride-channel mutations in six new North American families with X-linked nephrolithiasis. Kidney international 54:698-705.

Hoopes RR Jr, Raja KM, Koich A, Hueber P, Reid R, Knohl SJ, Scheinman SJ. 2004. Evidence for genetic heterogeneity in Dent's disease. Kidney international 65:1615-20.

Igarashi T, Gunther W, Sekine T, Inatomi J, Shiraga H, Takahashi S, Suzuki J, Tsuru N, Yanagihara T, Shimazu M, Jentsch TJ, Thakker RV. 1998. Functional characterization of renal chloride channel, CLCN5, mutations associated with Dent'sJapan disease. Kidney international 54:1850-6. 
Kelleher CL, Buckalew VM, Frederickson ED, Rhodes DJ, Conner DA, Seidman JG, Seidman CE. 1998. CLCN5 mutation Ser244Leu is associated with $\mathrm{X}$-linked renal failure without $\mathrm{X}$-linked recessive hypophosphatemic rickets. Kidney international 53:31-7.

Lee BH, Lee SH, Choi HJ, Kang HG, Oh SW, Lee DS, Ha IS, Choi Y, Cheong HI. 2009. Decreased renal uptake of (99m)Tc-DMSA in patients with tubular proteinuria. Pediatr Nephrol 24:2211-2216.

Lloyd SE, Gunther W, Pearce SH, Thomson A, Bianchi ML, Bosio M, Craig IW, Fisher SE, Scheinman SJ, Wrong O, Jentsch TJ, Thakker RV. 1997. Characterisation of renal chloride channel, CLCN5, mutations in hypercalciuric nephrolithiasis (kidney stones) disorders. Human molecular genetics 6:1233-9.

Lloyd SE, Pearce SH, Fisher SE, Steinmeyer K, Schwappach B, Scheinman SJ, Harding B, Bolino A, Devoto M, Goodyer P, Rigden SP, Wrong O, et al. 1996. A common molecular basis for three inherited kidney stone diseases. Nature 379:445-9.

Ludwig M, Doroszewicz J, Seyberth HW, Bokenkamp A, Balluch B, Nuutinen M, Utsch B, Waldegger S. 2005. Functional evaluation of Dent's disease-causing mutations: implications for $\mathrm{ClC}-5$ channel trafficking and internalization. Human genetics 117:228-37.

Ludwig M, Utsch B, Monnens LA. 2006. Recent advances in understanding the clinical and genetic heterogeneity of Dent's disease. Nephrol Dial Transplant 21:2708-17.

Mansour-Hendili L, Blanchard A, Le Pottier N, Roncelin I, Lourdel S, Treard C, Gonzalez W, Vergara-Jaque A, Morin G, Colin E, Holder-Espinasse M, Bacchetta J, et al. 2015. Mutation Update of the CLCN5 Gene Responsible for Dent Disease 1. Human mutation 36:743-52.

Morimoto T, Uchida S, Sakamoto H, Kondo Y, Hanamizu H, Fukui M, Tomino Y, Nagano N, Sasaki S, Marumo F. 1998. Mutations in CLCN5 chloride channel in Japanese patients with low molecular weight proteinuria. J Am Soc Nephrol 9:811-8.

Oudet C, Martin-Coignard D, Pannetier S, Praud E, Champion G, Hanauer A. 1997. A second family with XLRH displays the mutation S244L in the CLCN5 gene. Hum Genet 99:781-784.

Park E, Choi HJ, Lee JM, Ahn YH, Kang HG, Choi YM, Park SJ, Cho HY, Park Y-H, Lee SJ, Ha IS, Cheong HI. 2014. Muscle involvement in Dent disease 2. Pediatr Nephrol 29:2127-2132.

Ramos-Trujillo E, Claverie-Martin F, Garcia-Nieto V, Ariceta G, Vara J, Gonzalez-Acosta H, Garcia-Ramirez M, Fons J, Cordoba-Lanus E, Gonzalez-Paredes J, Valenciano B, Ramos L, et al. 2013. Dent's disease: Identification of seven new pathogenic mutations in the CLCN5 gene. J Pediatr Genet 2:133-140.

Ramos-Trujillo E, Gonzalez-Acosta H, Flores C, Garcia-Nieto V, Guillen E, Gracia S, Vicente C, Espinosa L, Maseda MA, Santos F, Camacho JA, Claverie-Martin F. 2007. A missense mutation in the chloride/proton CIC-5 antiporter gene results in increased expression of an alternative mRNA form that lacks exons 10 and 11. Identification of seven new CLCN5 mutations in patients with Dent's disease. Journal of human genetics 52:255-61.

Samardzic M, Pavicevic S, Ludwig M, Bogdanovic R. 2011. Effect of growth hormone replacement therapy in a boy with Dent's disease: a case report. J Med Case Rep 5:400.

Scheinman SJ, Cox JP, Lloyd SE, Pearce SH, Salenger PV, Hoopes RR, Bushinsky DA, Wrong O, Asplin JR, Langman CB, Norden AG, Thakker RV. 2000. Isolated hypercalciuria with mutation in CLCN5: relevance to idiopathic hypercalciuria. Kidney Int 57:232-239.

Sekine T, Komoda F, Miura K, Takita J, Shimadzu M, Matsuyama T, Ashida A, Igarashi T. 2014. Japanese Dent disease has a wider clinical spectrum than Dent disease in Europe/USA: genetic and clinical studies of 86 unrelated patients with low-molecular-weight proteinuria. Nephrol Dial Transplant 29:376-384.

Takemura T, Hino S, Ikeda M, Okada M, Igarashi T, Inatomi J, Yoshioka K. 2001. Identification of two novel mutations in the CLCN5 gene in Japanese patients with familial idiopathic low molecular weight proteinuria (Japanese Dent's disease). Am J Kidney Dis 37:138-143. 
Tanuma A, Sato H, Takeda T, Hosojima M, Obayashi H, Hama H, lino N, Hosaka K, Kaseda R, Imai N, Ueno M, Yamazaki M, et al. 2007. Functional characterization of a novel missense CLCN5 mutation causing alterations in proximal tubular endocytic machinery in Dent's disease. Nephron 107:p87-97.

Tosetto E, Ceol M, Mezzabotta F, Ammenti A, Peruzzi L, Caruso MR, Barbano G, Vezzoli G, Colussi G, Vergine G, Giordano M, Glorioso N, et al. 2009. Novel mutations of the CLCN5 gene including a complex allele and A 5' UTR mutation in Dent disease 1. Clin Genet 76:413-416.

Tosetto E, Ghiggeri GM, Emma F, Barbano G, Carrea A, Vezzoli G, Torregrossa R, Cara M, Ripanti G, Ammenti A, Peruzzi L, Murer L, et al. 2006. Phenotypic and genetic heterogeneity in Dent's disease--the results of an Italian collaborative study. Nephrol Dial Transplant 21:2452-63.

Wrong OM, Norden AG, Feest TG. 1994. Dent's disease; a familial proximal renal tubular syndrome with lowmolecular-weight proteinuria, hypercalciuria, nephrocalcinosis, metabolic bone disease, progressive renal failure and a marked male predominance. Qjm 87:473-93.

Wu F, Reed AA, Williams SE, Loh NY, Lippiat JD, Christie PT, Large O, Bettinelli A, Dillon MJ, Goldraich NP, Hoppe $B$, Lhotta K, et al. 2009. Mutational analysis of CLC-5, cofilin and CLC-4 in patients with Dent's disease. Nephron 112:p53-62.

Zhu B, Li P, Huang J. 2010. [Clinical and genetic analysis of Dent's disease in 6 Chinese children with low molecular weight proteinuria]. Zhonghua Er Ke Za Zhi 48:329-333. 
Supp. Table S2. Distance between the residues L266, S270, Y272, F273 and the "proton glutamate" or the "gating glutamate" in chains A or B during the MD simulations in the CIC-5 homology model based on $\mathrm{C}$. merolae ClC channel.

\begin{tabular}{|c|c|c|c|c|c|c|c|c|c|}
\hline \multicolumn{2}{|c|}{ E268 } & \multicolumn{2}{c|}{273} & \multicolumn{2}{c|}{266} & \multicolumn{2}{c|}{270} & \multicolumn{2}{c|}{272} \\
\cline { 3 - 10 } \multicolumn{2}{|c|}{ WT A } & B & A & B & A & B & A & B \\
\hline \multirow{2}{*}{ WT } & Average & 11,52 & 12,42 & 6,15 & 6,34 & 6,22 & 6,16 & 11,08 & 10,95 \\
\cline { 2 - 11 } & $\begin{array}{c}\text { Standard } \\
\text { Deviation }\end{array}$ & 1,17 & 0,74 & 0,27 & 0,23 & 0,23 & 0,37 & 0,49 & 0,72 \\
\hline
\end{tabular}

\begin{tabular}{|c|c|c|c|c|c|c|c|c|c|}
\hline \multicolumn{2}{|c|}{ E211 } & \multicolumn{2}{c|}{273} & \multicolumn{2}{c|}{266} & \multicolumn{2}{c|}{270} & \multicolumn{2}{c|}{272} \\
\cline { 2 - 11 } & A & B & A & B & A & B & A & B \\
\hline \multirow{2}{*}{ WT } & Average & 21,89 & 20,55 & 16,13 & 14,44 & 17,04 & 14,62 & 22,68 & 20,40 \\
\cline { 2 - 11 } & $\begin{array}{c}\text { Standard } \\
\text { Deviation }\end{array}$ & 0,69 & 0,44 & 1,12 & 0,62 & 1,41 & 0,39 & 1,04 & 0,39 \\
\hline
\end{tabular}


Supp. Table S3. Main clinical traits at diagnosis from patients with Dent's disease 1, harbouring class 1,2 or 3 CIC -5 mutants. Proton Glutamate mutants refer to $\mathrm{ClC}-5$ mutations surrounding the region of E268 selected for this study. No statistically significant difference was observed for these 3 qualitative traits when all patients of each class are compared using Chi-square test ( $p=0.71$ for nephrocalcinosis, $\mathrm{p}=0.07$ for rickets and $\mathrm{p}=0.15$ for renal impairment).

\begin{tabular}{|l|l|l|l|l|l|l|l|l|l|}
\hline & \multicolumn{3}{|l}{ Nephrocalcinosis } & \multicolumn{3}{l|}{ Rickets } & \multicolumn{3}{l|}{ Renal Impairment } \\
\hline & Yes & No & NA & Yes & No & NA & Yes & No & NA \\
\hline $\begin{array}{l}\text { Proton } \\
\text { Glutamate } \\
\text { mutants class 1 }\end{array}$ & $1 / 4$ & $2 / 4$ & $1 / 4$ & $2 / 4$ & $1 / 4$ & $1 / 4$ & $1 / 4$ & $3 / 4$ & - \\
\hline $\begin{array}{l}\text { Proton } \\
\text { Glutamate } \\
\text { mutants class 2 }\end{array}$ & $1 / 1$ & - & - & - & $1 / 1$ & - & - & $1 / 1$ & - \\
\hline $\begin{array}{l}\text { Proton } \\
\text { Glutamate } \\
\text { mutants class 3 }\end{array}$ & - & $1 / 4$ & $3 / 4$ & $1 / 4$ & $2 / 4$ & $1 / 4$ & - & $2 / 4$ & $2 / 4$ \\
\hline $\begin{array}{l}\text { Other mutants } \\
\text { class 1 }\end{array}$ & $26 / 45$ & $14 / 45$ & $5 / 45$ & $4 / 45$ & $26 / 45$ & $15 / 45$ & $7 / 43$ & $33 / 43$ & $3 / 43$ \\
\hline $\begin{array}{l}\text { Other mutants } \\
\text { class 2 }\end{array}$ & $6 / 11$ & $5 / 11$ & - & $3 / 11$ & $6 / 11$ & $2 / 11$ & $2 / 11$ & $7 / 11$ & $2 / 11$ \\
\hline $\begin{array}{l}\text { Other mutants } \\
\text { class 3 }\end{array}$ & $18 / 35$ & $16 / 35$ & $1 / 35$ & $11 / 35$ & $17 / 35$ & $7 / 35$ & $11 / 35$ & $17 / 35$ & $7 / 35$ \\
\hline
\end{tabular}

